\title{
Intelligent lightweight structures for hybrid machine tools
}

\author{
H. -Christian Möhring ${ }^{1}$ (1) $\cdot$ Matthias Müller ${ }^{2}$ Jens Krieger ${ }^{3} \cdot$ Jörg Multhoff $^{3} \cdot$ Christian Plagge $^{4} \cdot$ Jesper de Wit $^{5}$. \\ Sandra Misch ${ }^{6}$
}

Received: 28 December 2019 / Accepted: 22 September 2020 / Published online: 24 October 2020

(c) The Author(s) 2020

\begin{abstract}
In order to improve the competitiveness on the global machine tool markets, a permanent development of new solutions and optimization of existing technologies is necessary. Besides traditional business areas, like Europe, Asia and the US, emerging countries provide interesting potential. Currently, the setup and operation of precise machine tools in these areas possesses some challenges. As an example, the foundation of the machines is often not as stable as assumed during the layout and design phase. Furthermore, the thermal boundary conditions are often characterized by much higher differences of the ambient temperature during the daily operational time compared to European conditions. These influences affect especially the performance of medium sized machine tools. Within the joint project HYBRID ${ }^{\mathrm{i}}$, funded by the Federal Ministry of Education and Research (BMBF) supported by the Projektträger Karlsruhe (PTKA), partners from industry and research created, realized and investigated new intelligent lightweight machine slide structures in order to overcome the named challenges. In particular, two variants of a hybrid material z-slide (RAM) with integrated sensors were built and analyzed with respect to advantages in terms of mass reduction, static and dynamic stiffness, dynamic positioning accuracy as well as thermal behavior. This paper presents the developments and results of the project.
\end{abstract}

Keywords Machine tool $\cdot$ Lightweight structure $\cdot$ Dynamic behavior $\cdot$ Thermal behavior $\cdot$ Sensor integration

\section{Introduction}

In order to develop new markets in machine tools business, emerging countries become more important [1]. Due to the existing infrastructure, the setup and operation of precise machine tools in these areas often possesses some severe challenges. Many a time, machine tools are placed at foundations, which are not adequately dimensioned considering the static and dynamic requirements of the machines.

H. -Christian Möhring

hc.moehring@ifw.uni-stuttgart.de

Matthias Müller

MMueller@fooke.de

Jens Krieger

j.krieger@isatec-aachen.de

Jörg Multhoff

j.multhoff@isatec-aachen.de

Christian Plagge

C.Plagge@t-eon.de

Jesper de Wit

Jesper.deWit@invent-gmbh.de
As a consequence, the dynamic performance in terms of accelerations and jerk limits of feed axis has to be reduced consciously. Furthermore, often the thermal boundary conditions are characterized by differences of the ambient temperature during daily operational time that are much higher than those in the European area. Thus, thermal induced structural deformations occur and provoke inaccuracies in the positioning behavior of the machine. These influences affect the performance of the machine tools significantly.

Sandra Misch

sandra.misch@ovgu.de

1 Institut für Werkzeugmaschinen, Universität Stuttgart, Stuttgart, Germany

2 FOOKE GmbH, Borken, Germany

3 ISATEC GmbH, Aachen, Germany

4 TEON GmbH, Braunschweig, Germany

5 INVENT GmbH, Braunschweig, Germany

6 Institut für Fertigungstechnik und Qualitätssicherung, Otto-von-Guericke-Universität Magdeburg, Magdeburg, Germany 


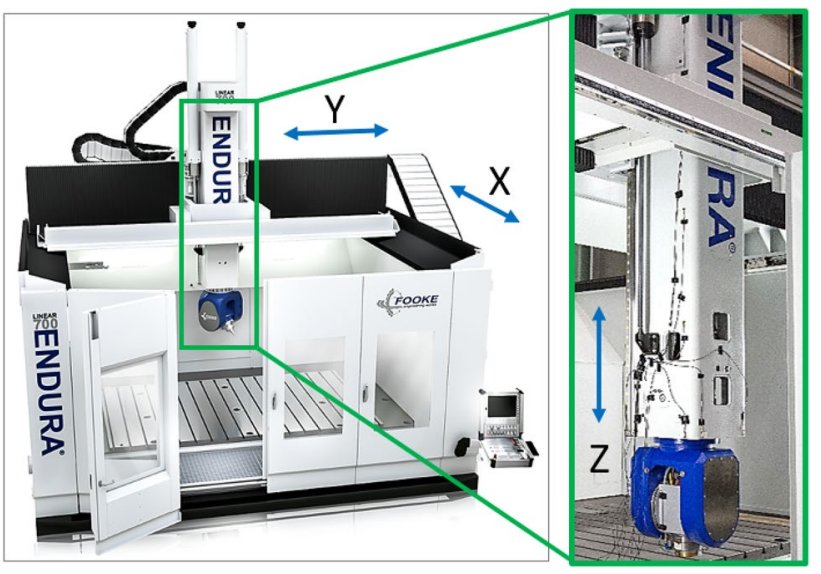

Fig. 1 ENDURA® 700LINEAR with vertical z-slide [FOOKE]

This especially applies to medium size machine tools with a workspace of e.g. $2200 \times 3500 \times 1500 \mathrm{~mm}^{3}$. Such machines are commonly designed as gantry type machines with a base plate, two side walls, a moving bridge ( $\mathrm{x}$-axis) that carries a cross slide (y-axis) and a vertically moving RAM (z-slide) (Fig. 1).

The here involved company FOOKE provides this type of machine tools equipped with direct drives in all 5 feed axes that feature high positioning dynamics and accuracy. With respect to the dynamic stiffness and traverse path accuracy, the machine performance can be affected by an insufficiently dimensioned foundation. Furthermore, a sensitivity to changing ambient temperature conditions is given due to the size of the machine structural elements and length of lever arms.

Against this background, within the joint project HYBRID ${ }^{i}$, the companies FOOKE, INVENT, ISATEC and TEON as well as the Institute of Manufacturing Technology and Quality Management (IFQ, Otto-von-GuerickeUniversity Magdeburg) cooperatively created and investigated new lightweight hybrid material slide components with integrated sensors as an approach to overcome the challenges mentioned above. As an exemplary machine element, the z-slide was chosen due to its essential contribution to the overall dynamic and thermal behavior of the machine. The major aim was to reduce the dynamic excitation of the machine structure by accelerations of the slide. For this, a significant mass reduction of the machine component had to be achieved. At the same time, the static stiffness had to be kept comparable with the conventional casted slide. In addition, the lightweight design of the slide shall provide an improved thermal stability with respect to changes of the ambient condition. Furthermore, by means of structure integrated sensors, the structural behavior of the slide component shall be monitored during operation in order to enable control based compensation approaches to further increase the accuracy of the machine tool. The principle approach incorporates the application of fiber reinforced (carbon and glass fiber reinforced plastics, CFRP and GFRP) and composite materials (in particular hollow sphere composites) in combination with steel elements and substructures. With respect to sensor integration, the realization of printed conducting paths and their integration into the hybrid material slide component was aspired. This paper presents the developments and results of the HYBRID ${ }^{i}$ project recapitulatory.

\section{State of the art}

In order to lower inertia, to relieve the feed drive systems, to enhance the feed motion dynamics and path accuracy, and to improve the energy efficiency, lightweight design provides a high potential in the machine tool sector. Lightweight design comprises either a structural optimization in terms of the topology and wall thicknesses of structural components or the application of lightweight materials such as CFRP, GFRP and composites, or even a combination of both approaches. A comprehensive overview of the state of the art regarding the application of materials and structural optimization for machine tools is given in [2,3]. Besides the lower density and higher specific stiffness of CFRP compared to cast iron and steel, higher material damping properties and thermal expansion coefficients close to zero can be exploited in machine component design [4]. As a consequence of the buildup and internal structure of composite parts, including fibers and matrix, by exploiting the design degrees of freedom regarding the types of fibers, fiber orientation and layer composition, quasi-isotropic or targeted anisotropic mechanical and thermal characteristics can be created. In order to gain the full potential of these properties, sophisticated design, layout and optimization methods as well as modelling and simulation techniques are required [3]. Against the background of the broad range of commercially available fiber materials and their mechanical and thermal properties, the related cost have to be considered as an additional optimization parameter.

Jung et al. investigated the design of a hybrid compositealuminum beam structure with high modulus (HM) carbon/ epoxy composites with respect to the design of a LCD glass panel inspection machine [5]. The layout was optimized in terms of the cross section shape of the beam, the stacking sequence and the thickness of the composite reinforcement with respect to the fundamental natural frequency and bending deformation. The beneficial dynamic properties of composites were exploited by Lee et al. with respect to the design of a guiding arm of an electrical discharge wire cutting machine [6]. With the support of Finite Element (FE) simulations, the detailed design regarding bonding length and number of reinforcing plies was conducted. Compared 
to the conventional arm, the mass was reduced to less than $50 \%$, the static stiffness was maintained and the fundamental natural frequency as well as the damping ratio were significantly improved.

With respect to the design of machine tools for material removal operations, various investigations were carried out and prototypes were built in order to achieve the best compromise between mass reduction, static stiffness, fundamental natural frequencies, damping ratios as well as thermal stability. Besides more or less pure composite structures, the majority of approaches considers hybrid approaches in which different materials are combined. A hybrid steelcomposite headstock for high-precision grinding machines was analyzed by Chang et al. [7]. The composite reinforcement led to an improvement of the dynamic stiffness and damping in the higher frequency range of $100-500 \mathrm{~Hz}$. Suh and Lee presented the design of a hybrid material slide structure with composite reinforcements $[8,9]$. The first natural frequency was increased from 64 to $92 \mathrm{~Hz}$ and the damping factors for the first 5 modes were enhanced by up to more than $100 \%$. The strength of the adhesively bonded sandwich structure of the horizontal moving body was analyzed in [10]. Furthermore, the thermal properties of the composite sandwich were investigated. In [11], carbon/ epoxy composite-aluminum hybrid structures with friction layers were applied with the aim to achieve a high structural damping. The static deflection and first natural frequency were analyzed regarding the stacking angle and thickness of the composite. Between the aluminum and composite interface, a friction damping layer was inserted. Composite reinforcements, the use of composite sandwich materials and composite-foam-resin concrete sandwich structures were analyzed in [12-14], respectively. Kulisek et al. performed case studies on rams with, on the one hand, a thick-walled composite body and minimal amount of steel as well as, on the other hand, a hybrid structure with fiber composites and cork layers [15]. Fleischer, et al. and Koch et al. filled a composite machine slide with different amounts of fluids in order to control the structural dynamics during machine utilization [16, 17]. A serious aspect especially for hybrid combinations of materials with different thermal expansion coefficient concerns thermally induced mechanical stresses in the interfaces and joints which can lead to de-bonding and a loss of structural stiffness. Residual stresses in material interfaces can already occur during the curing of the composite parts [18-22]. The characteristics of composite structures are influenced by the joints, e.g. towards metal parts as interfaces for guides, drives or machine components. The layout of mechanically fastened joints has to be carried out carefully in order to avoid structural damage of the composite elements [23]. Composite material structures are suitable for inherent sensor and actuator integration. On the one hand, integrated sensors can be used for structural health monitoring [24]. Integrated sensors also provide relevant information for machine and process state monitoring. Meo et al. integrated fiber optic Bragg strain sensors into a ram of a vertical milling center in order to gather bending deformations and tool displacements during the process [25]. In $[26,27]$, piezo ceramic sensors are embedded in composite machine components. A printed circuit is integrated in [26] in order to realize the wiring of distributed sensors within the analyzed test specimen. Brecher et al. exploit the thermal stability of CFRP rods for a direct integrated measuring device for thermal state monitoring and compensation of thermally induced machine deflections [28]. The application of piezo sensor integrated CFRP structures in a workpiece clamping intelligent chuck system is introduced in [29]. The sensory piezo patch transducers are embedded in CFRP fingers which are pre-stressed against the workpiece during the clamping setup. Due to their high sensitivity, the sensors are capable to measure workpiece vibrations during the milling operations. By this, process monitoring regarding chatter occurrence becomes possible as well as an adaptive control of countermeasures.

As a summary, the advantageous material properties of CFRP have been analyzed with respect to machine tool applications already in the past. However, the comprehensive design, realization and analysis up to machining tests, as well as a comparison of variants of new lightweight machine slide components as conducted here cannot be found in literature. Considering that lightweight design approaches can either be used to reduce the mass of a component maintaining its stiffness or to improve the stiffness maintaining the mass, the investigation of different layouts of the same component reveals the range in which a technical optimization can be implemented. Furthermore, in contrast to previous studies, the work presented here includes the optimization of both mechanical and thermal properties of the exemplary component and also takes manufacturing costs into account. Integrated sensory elements show their sensitivity to mechanical loads acting on the slide component. In addition, with respect to the application in industrial machine tools, influences of chips and coolant lubricant on the performance of the machine component are studied herein. Finally, an analysis of machining results is presented that allows a comparison with the conventional casted machine slide.

\section{Design of lightweight machine slides}

The design of the exemplary prototype z-slides of the HYBRID $^{i}$ joint project started with a detailed analysis and definition of requirements. These requirements concern: a static stiffness comparable to the conventional casted component, a mass reduction by $25 \%$, improvement of the structural damping, improvement of the dynamic positioning 
Table 1 Morphology of principle approaches

\begin{tabular}{lllll}
\hline & Principle solutions & & & \\
\cline { 2 - 5 } Design approach & Tubings & Plates & Skeleton & Aramid \\
\hline Fiber & Carbon & Glass & Basalt & \\
Matrix & Epoxy & & Injection & \\
FRP production & Winding & Tape laying & Riveting & Clamping \\
Joining FRP/FRP & Gluing & Screwing & Riveting & Clamping \\
Joining FRP/Met. & Gluing & Screwing & & \\
Joining supports & Inserts & & GFRP contact & \\
Integration of guides & Metal contact & CFRP contact & GFRP contact & \\
Integr. of linear drive & Metal contact & CFRP contact & GFRP contact & \\
Integr. of mach. head & Metal contact & CFRP contact & GFRP contact & \\
Integr. of linear scale & Metal contact & CFRP contact & GFRP contact & \\
Integr. of counterweight & Metal contact & CFRP contact & HS composites & \\
Vibration damping & Absorber & Mass & Fix/Float bear. & \\
Red. of therm. deform. & Fiber orient. & Thermosym. & Fiber Bragg & \\
Sensor type & Strain gauge & Piezo transd. & Weaving & Stitching \\
Sensor integration & Appliqué & Laminate & Etching & \\
Wiring technology & Printing & Laminate & Unloaded & \\
Mounting windows & Loaded & & & \\
\hline & & & & \\
\hline
\end{tabular}
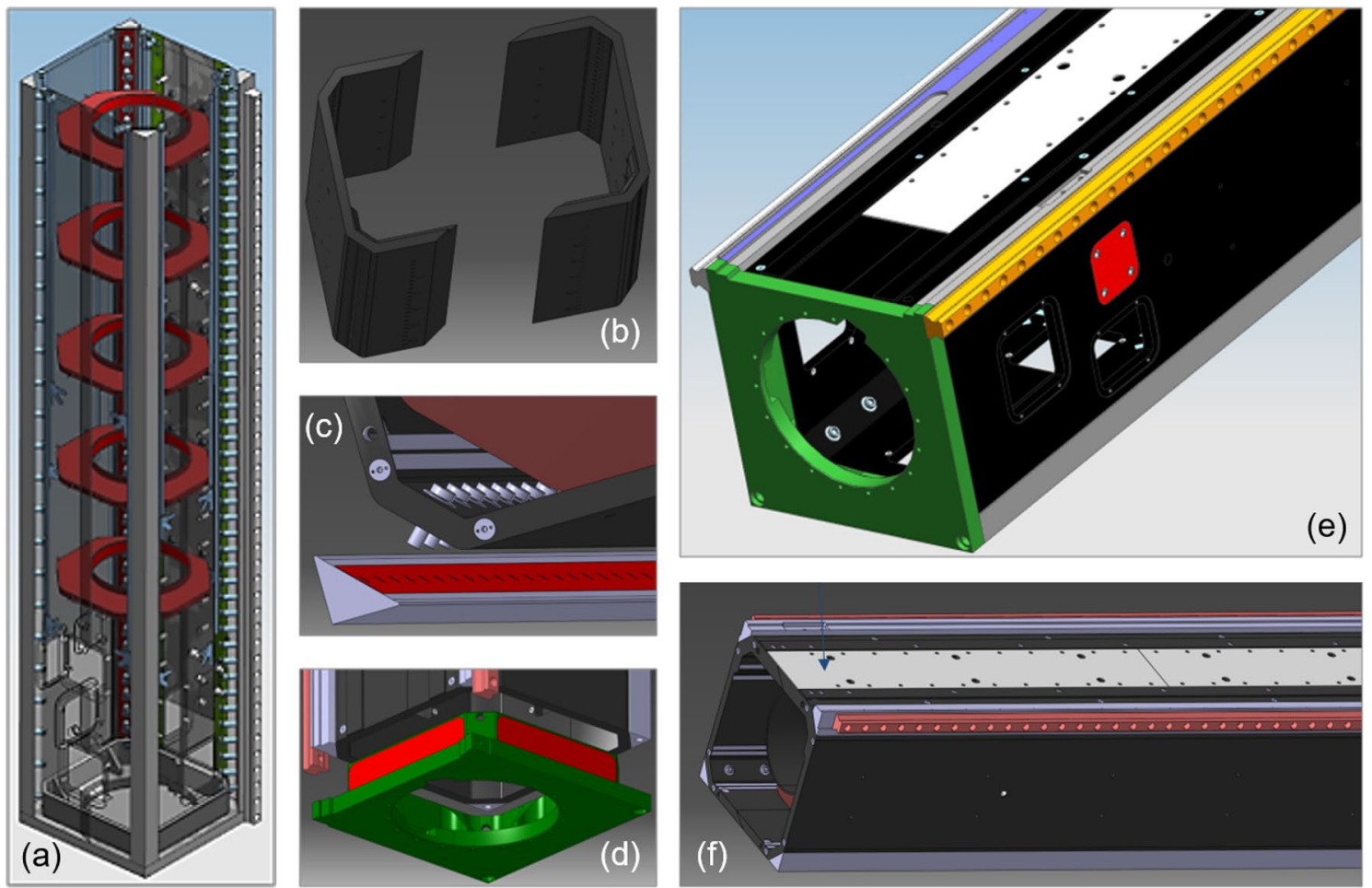

Fig. 2 Variant 1 with internal frames (a), glued CFRP half shells (b), mounting of the steel bars at the edges (c), steel connector plate to the machining head (d), assembly of the linear guides (e) and complete structure with inserted center tubing (f)

behavior (traverse path accuracy by 20\%) regarding jerk limits and transient overshoot, reduction of thermal induced displacements of the tool center point (TCP) by $20 \%$, sensor integration of machine and process monitoring, as well as the retention of interfaces towards linear guides, machining head, mounting windows, cross slide (y-axis) in order to allow the integration of the prototypes into an existing machine tool for machining tests. Based on this, various 
design approaches were analyzed by means of a morphology (Table 1).

Based on the morphology, two concepts were further developed:

Variant 1 (Fig. 2) is optimized with respect to the weight reduction by a high percentage of quasi-isotropic CFRP elements. The static stiffness, material and production cost have secondary relevance. The basic body consists of two wedged and glued half segments made of CFRP multilayer $\left(0^{\circ} \pm 45^{\circ} / 90^{\circ}\right)$ with a thickness of $24 \mathrm{~mm}$ and $40 \mathrm{~mm}$, respectively. The backside wall has an increased thickness in order to bear the attractive force of the linear drive and to transfer the process loads to the linear guides. Steel bars at the edges of the body improve the stiffness and thermal symmetry of the component. Also, the linear guides are screwed to the steel bars on the backside of the slide. Internal aluminum frames increase the shear and torsional stiffness. The connection to the machining head is realized by a steel adapter plate at the slide bottom. The bars, frames and adapter plate are glued with the CFRP body and screwed in addition. Finally, a CFRP center tubing is inserted and glued with the internal frames. The screw holes within the CFRP elements are supported by inserts. This component was predominantly designed and optimized by means of Finite Element calculations of the mechanical (stiffness) and thermal characteristics by INVENT.

Variant 2 (Fig. 3) is optimized with respect to the static stiffness, material and production cost. The reduction of weight has secondary relevance. The percentage of CFRP elements is lower and these elements are less complex regarding manufacturing. A modified version of the conventional casted slide component is used as a skeleton. Four equally dimensioned multilayered CFRP plates with a thickness of $17 \mathrm{~mm}$ are inserted and glued into milled pockets at the side walls, where only a minimum remaining wall thickness of the metal part is kept. In order to improve the bonding of the CFRP plates with the casted slide body, a stepped geometry of the milled pockets is chosen. Besides the stiffness requirements, also the desired improvement of the thermal stability is achieved by a specific arrangement of
Fig. 3 Variant 2 with realization steps and milled pocket structure for CFRP plate integration

\section{Conventional casted slide}

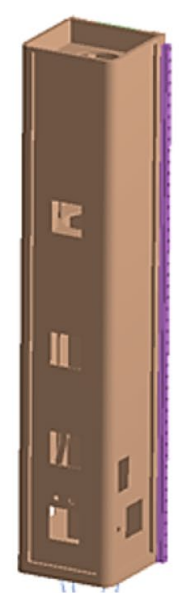

\section{Body with glued side walls $\square$ of main interfaces}

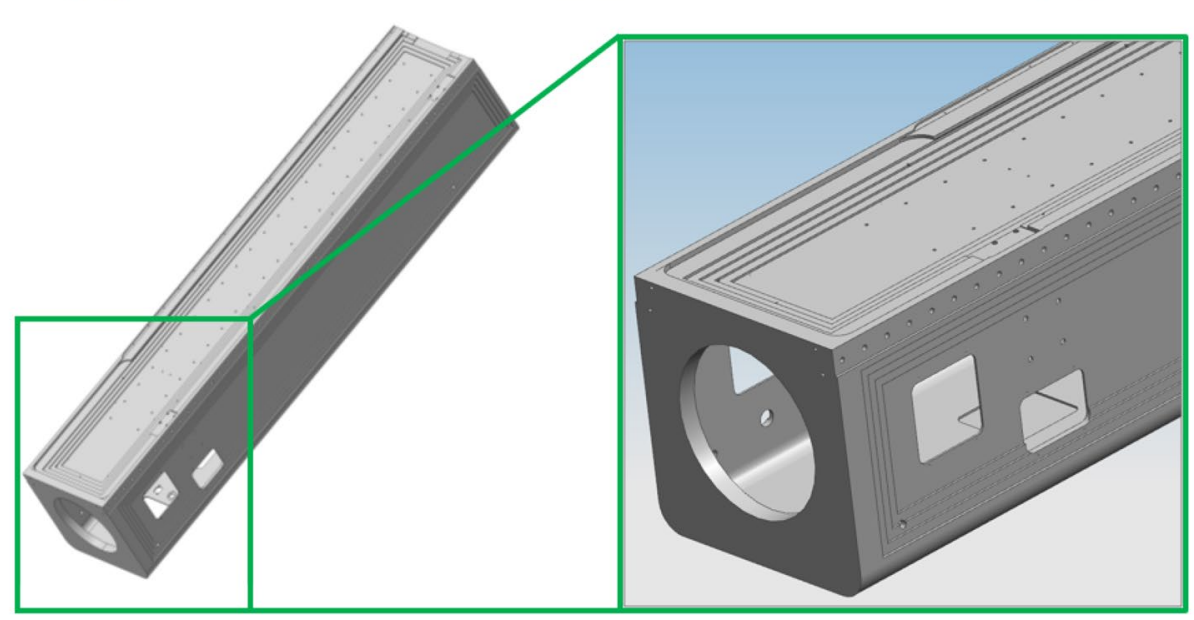




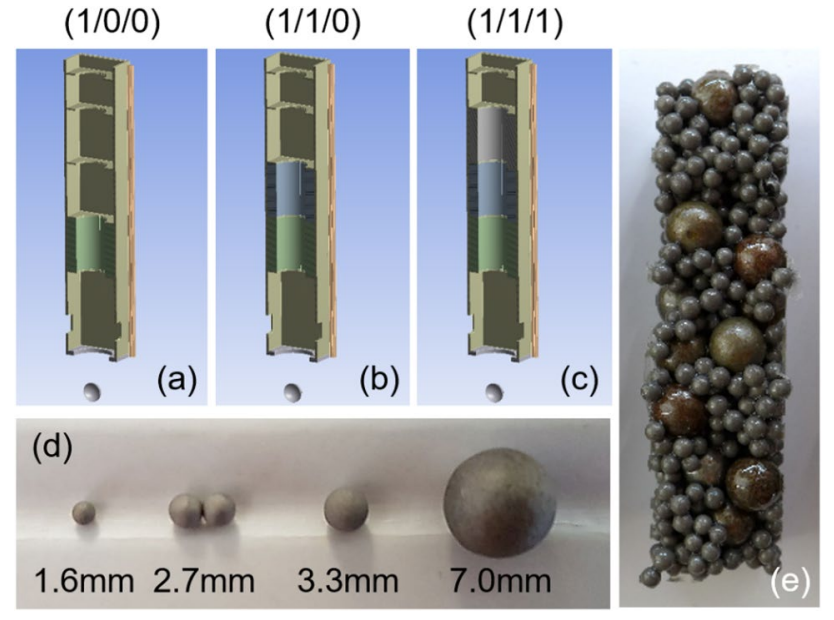

Fig. 4 Variations of damping filling with hollow sphere composites

fiber orientations inside the CFRP plates, that was optimized by ISATEC. The front, rear and side plates have different percentages of fiber orientations in order to achieve a high stiffness but low thermal deformation. This is realized by multiple layers of unidirectional (UD) CFRP material which allows a more individual buildup compared with woven fabrics. A relatively high mass per unit area was chosen in order to minimize the number of layers which have to be cut and placed into the mold. This contributes to low manufacturing cost. Furthermore, in order to increase the structural damping, an internal filling of the cavities between the slide body and the center tubing with different variations of metal hollow sphere composites (HSC) was investigated by simulation and experiment by the IFQ (Fig. 4); see Sect. 5 .

In order to allow a comparison of both variants, the same UHM-fibers (ultra high modulus) were applied. The use of UHM-fibers also contributes to a high overall stiffness of the $\mathrm{z}$-slide.

The static, dynamic and thermal behavior of various design concepts and alternative variations was modelled and simulated by ISATEC. In a first step, based on a Finite
Element (FE) model of the existing casted slide, reference values with respect to the stiffness and natural frequencies were derived. Subsequently, the hybrid material slide concepts were assessed against these values. Furthermore, an optimization of Variant 2 regarding mechanical and thermal properties was conducted. Within the simulations, the machining head was assumed as a rigid point mass that is connected rigidly to the z-slide corresponding to the lever arm of the center of gravity of the real component. The analyses were implemented assuming the z-slide in its lowest position since this provides the highest sensitivity and compliance. Virtual process forces were induced at the TCP, again considering the lever arm derived from the real geometry, in order to allow the comparison with the reference z-slide. The following optimization steps were carried out:

- Static analysis under lateral force loads ( $\mathrm{x}$ - and $\mathrm{y}$-direction)

- Static analysis under normal force loads at the secondary part of the linear drive (magnetic attraction force)

- Thermoelastic analysis under homogeneous warming of the complete $\mathrm{z}$-slide

- Thermoelastic analysis under local warming of the secondary part of the linear drive considering convective heat transfer boundary conditions for the parts of the slide

- Modal analysis of the unsupported z-slide without attaching parts

- Modal analysis of the supported z-slide with fixed boundary conditions at the interfaces towards the machine tool considering all attaching parts

By means of an individual variation of the layer buildup for the front, rear and side walls, the requirements regarding stiffness an thermal compliance in lateral direction and natural frequencies could be met. The optimized z-slide was integrated into a simulation model of the complete machine structure in a second step. The dynamic behavior of this
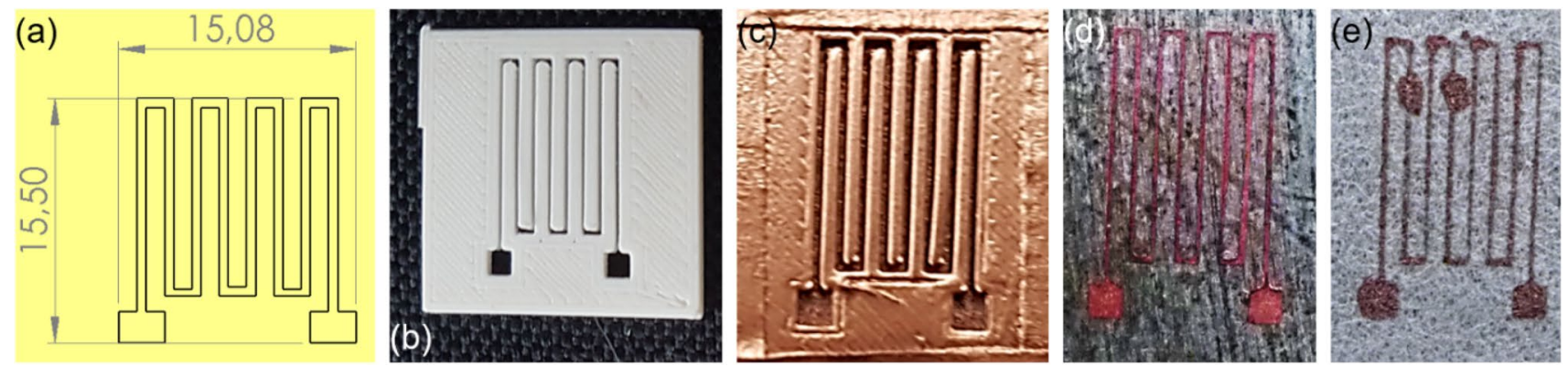

Fig. 5 Printing of strain gauge structures with copper spray and additively manufactured mask; basic geometry (a), printing mask (b), copper spray printing (c), printed structure on plastic substrate (d), printed structure on fleece 
integrated model was analyzed by modal analysis and frequency analysis with harmonic excitation at the TCP.

\section{Sensor integration}

In order to allow the monitoring of internal states of the z-slide as well as to observe machining conditions, the integration of sensors into the hybrid material slide structure was an additional aim of the HYBRID ${ }^{\mathrm{i}}$ joint project. Regarding the identification of structural deformations due to mechanical and thermal loads, strain sensitive sensors shall be implemented. In this regards, two approaches were followed: the integration of printed strain gauges [30] and the application of piezo patch transducers. With both approaches, a distributed sensor network was aspired with the goal to enable the recognition of structural deformations.

The printing of strain gauges and conducting paths was investigated by the IFQ in collaboration with TEON. On the one hand, the printing of copper spray using a mask was studied (Fig. 5).

Since the robustness of this printing process in terms of achieved conductivity and reproducibility was not satisfactory, on the other hand, the use of a material printer (type DIMATIX DMP-2850) for the production of electronic circuitry was analyzed (Fig. 6). Two types of silver nano particle ink (NBSIJ-MU01 and NBSIJ-FD02 by Mitsubishi Paper Mills Ltd.) were processed with different process settings in terms of voltage (10-25 V) and frequency $(5-40 \mathrm{kHz})$ of the printing head. As substrates, an inkjet foil (type GEHA F02) and a photo paper (type EPSON Premium Glossy) were

(a)

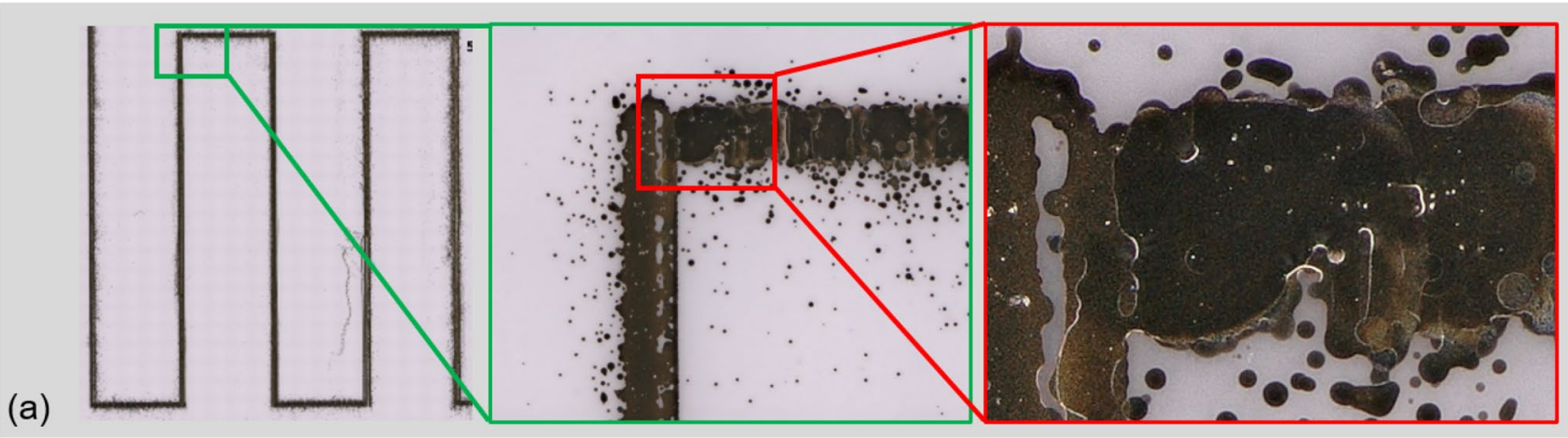

(b)

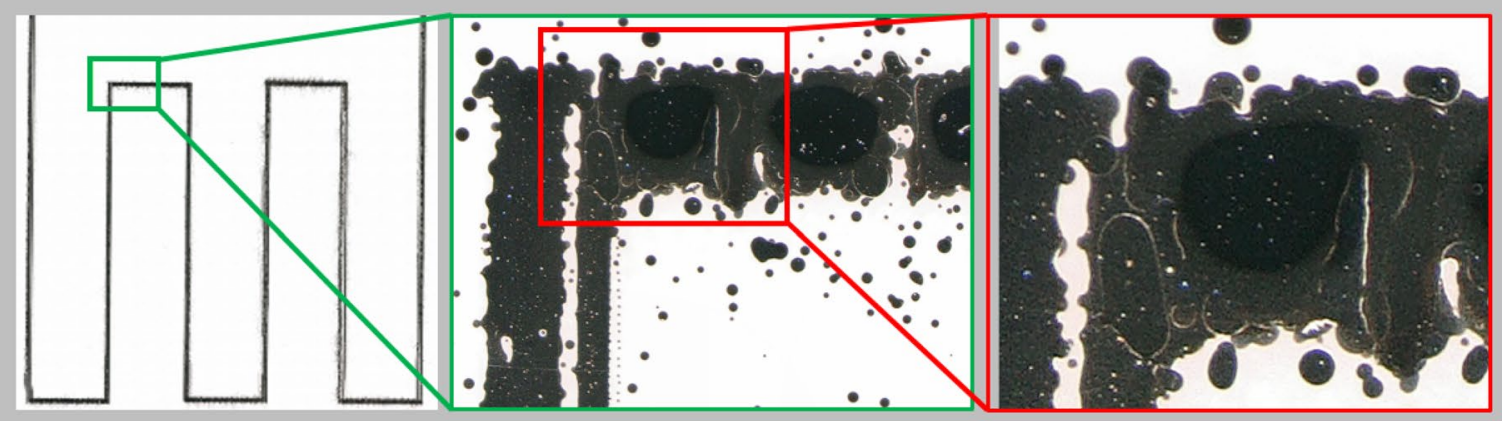

(c)
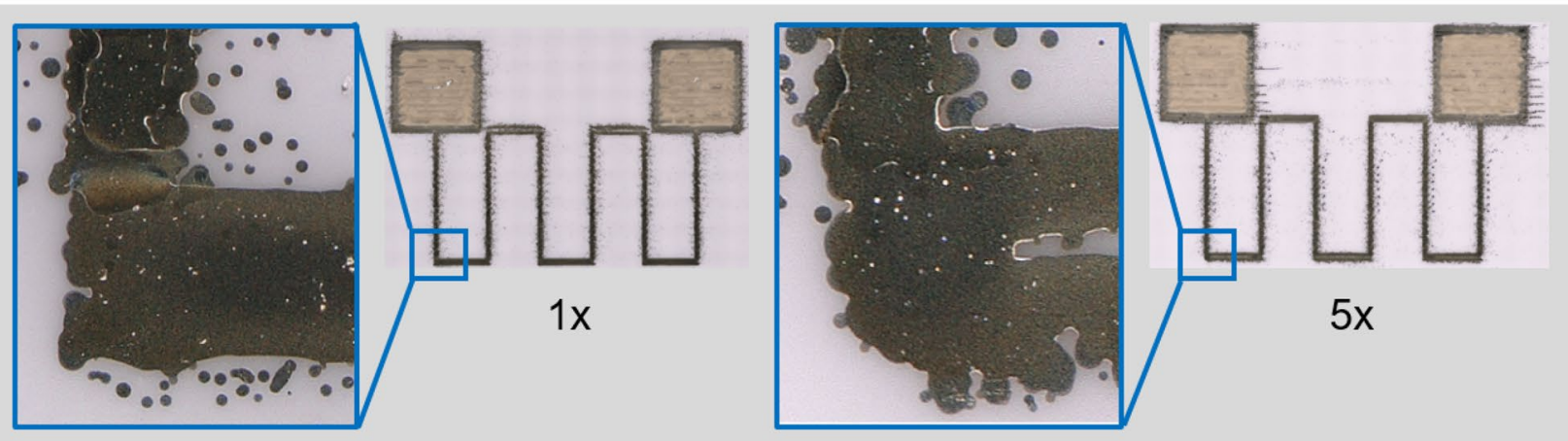

Fig. 6 Results of strain gauge printing tests with silver nano particle ink type FD02 on photo paper (a), inkjet foil (b) and photo paper with one or five overprints (c) 


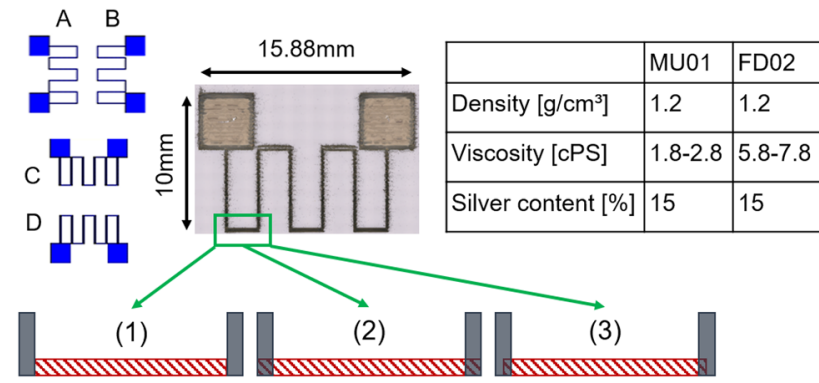

Fig. 7 Variations of the printing direction (a-d) and overlaps (1-3)
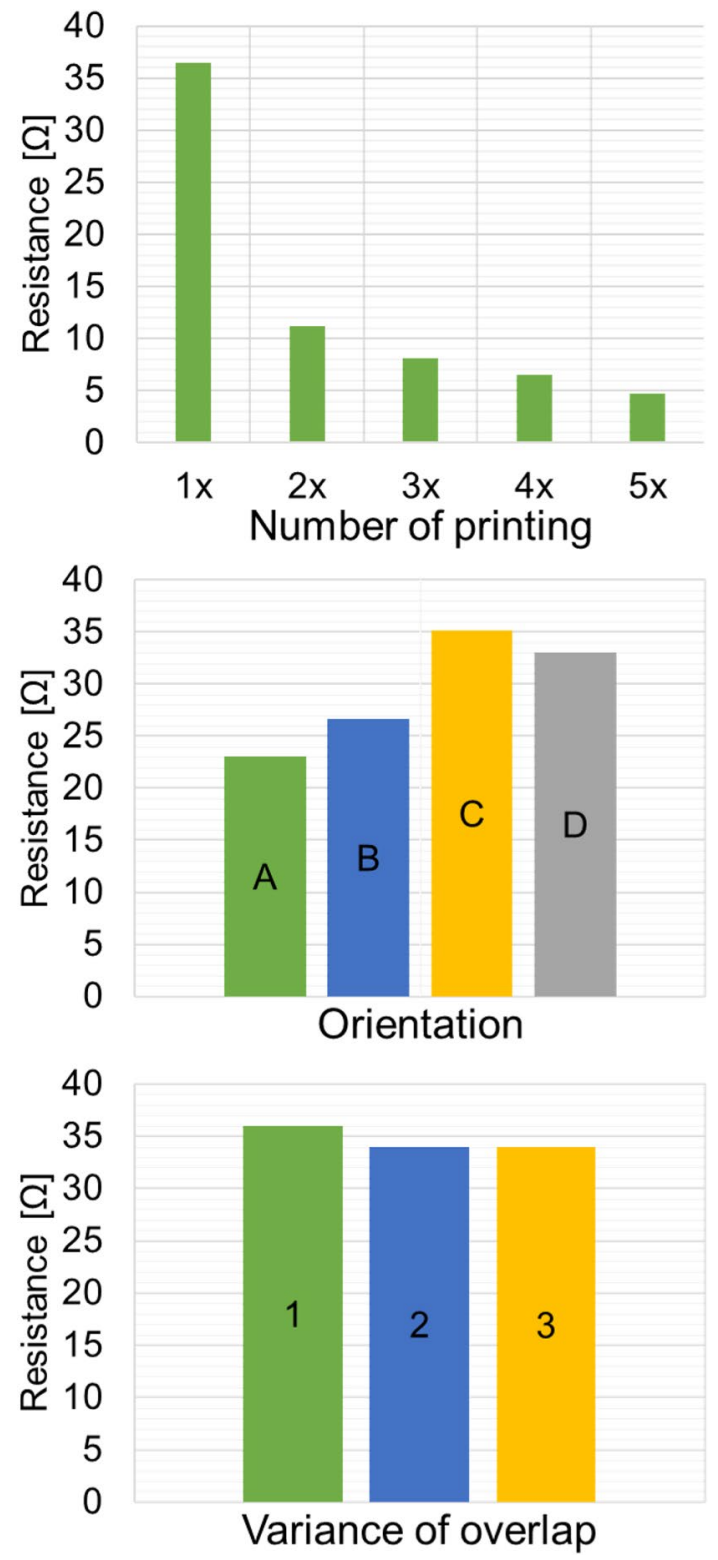

Fig. 8 Measured resistance of silver ink printing test specimen
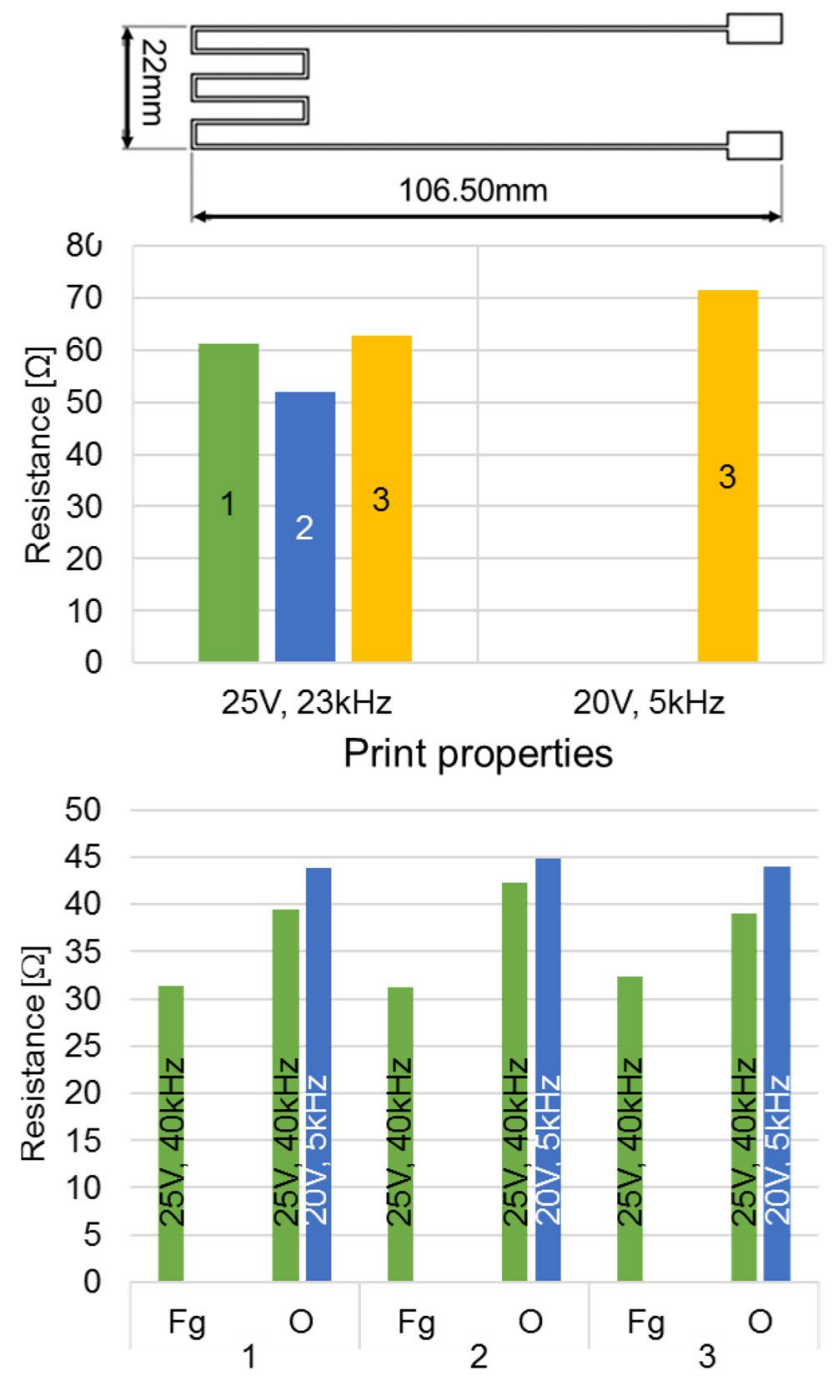

Fig. 9 Printed strain gauge test structures and measurement resistance values (1-3 characterize the type of overlap; Fg: photo paper; O: inkjet film)

applied. The cartridges of the printer have 16 nozzles with a spacing of $254 \mu \mathrm{m}$ and typical drop sizes of 1 and 10 pico liter. The drops have an interspace of $20 \mu \mathrm{m}$. The thickness of the conducting lines was $0.75 \mathrm{~mm}$.

As visible in Fig. 6, a distribution (splashing) of the silver particle ink occurs that can lead to gaps within the conducting lines and to incapable strain gauge structures. This challenge can be solved by appropriate printing parameters. In this respect, the repetitive printing of multiple line above each other was analyzed (Fig. 6c). Furthermore, the influence of the printing direction and different types of overlaps at the corners of the strain gauge structure were investigated (Fig. 7). The results in terms of the measured resistance of printed specimen are shown in Fig. 8.

The repetition of printing led to a decrease of the measured resistance. A remarkable sensitivity regarding the 

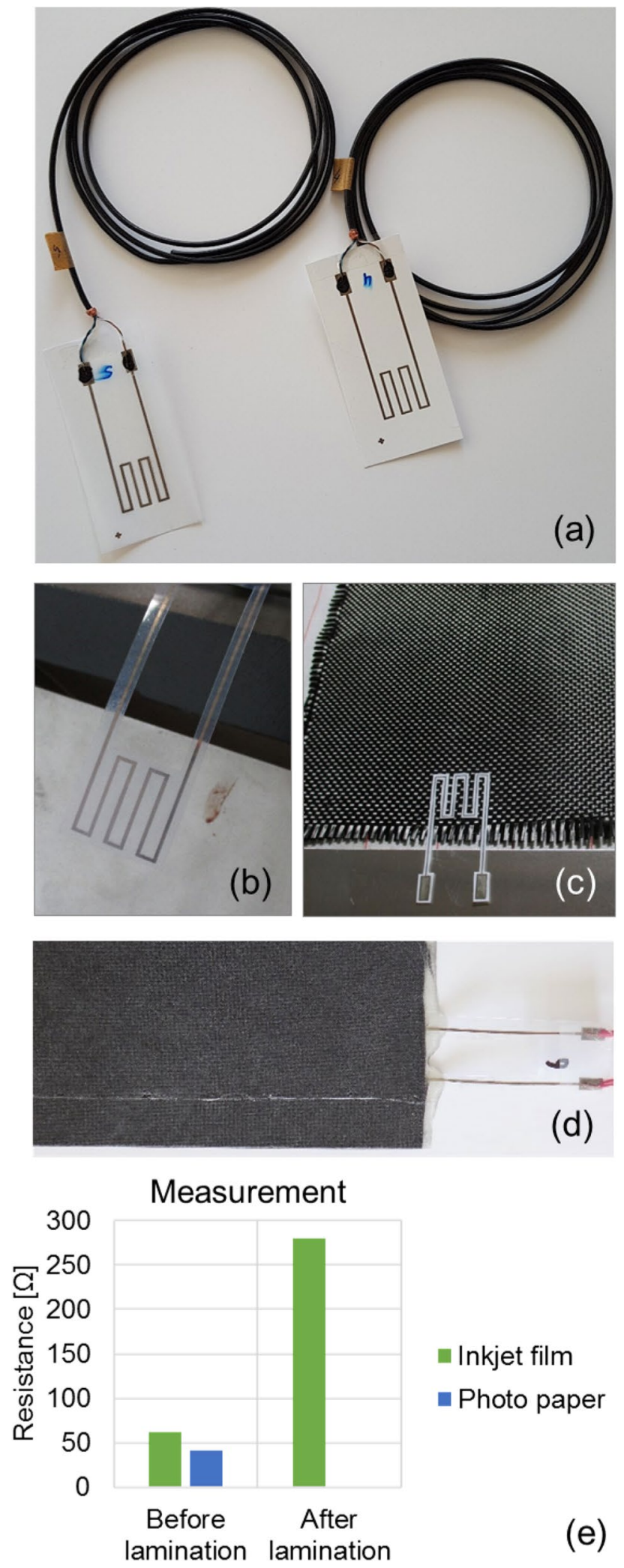

Fig. 10 Integration of printed strain gauge structures into a CFRP plate
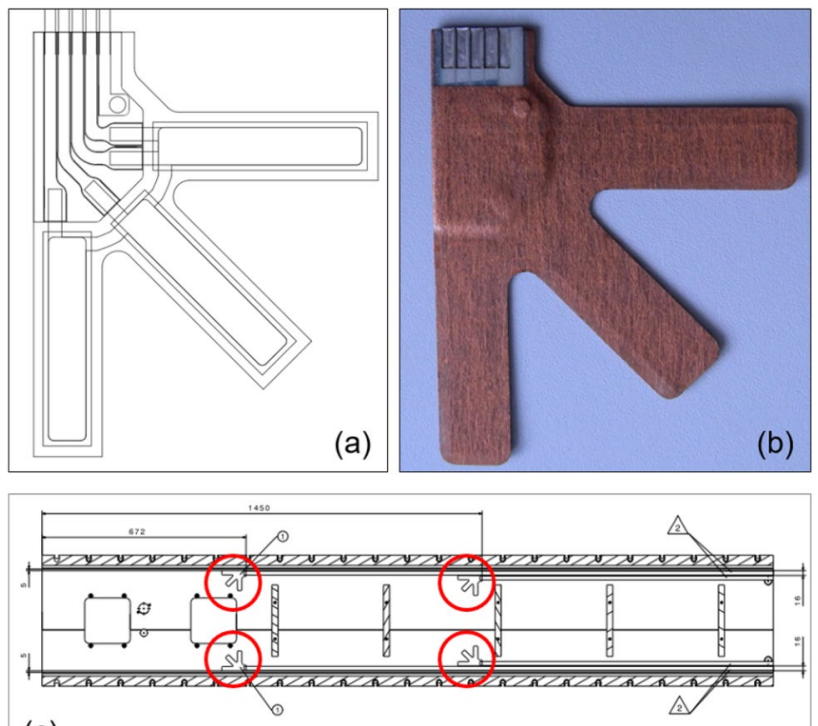

(c)

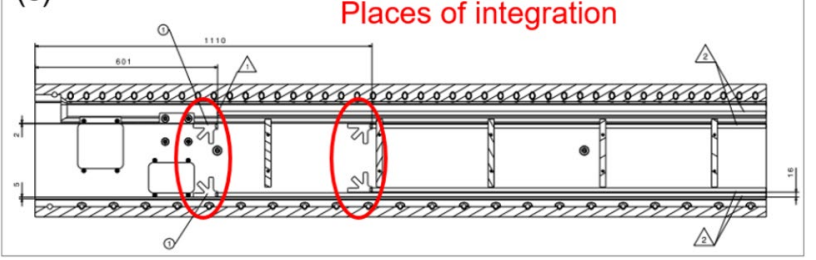

Fig. 11 Integration of piezo patch transducers

orientation of the structure within the workspace of the printer was observed. This indicates an anisotropic printing performance of the particular machine. The influence of overlapping is relatively small. The strategy without repetition and overlaps appeared to be the best solution. Based on these principle investigations, test structures for the integration into CFRP specimen were produced with a selected variety of printing parameters (Fig. 9). As a summary, the printing on inkjet film led to higher resistance. The type of overlap did not show a reproducible influence. Finally, some test structures were laminated into quasi-isotropic CFRP plates (Fig. 10). For this, the substrates of the strain gauge structures were cut close to the conducting lines in order to allow an appropriate bonding of the CFRP plate. After lamination, no measurements were possible with the photo paper supported structures. The analysis revealed a significant increase of the measurable resistance after lamination of the inkjet film supported printed structure.

As an alternative to the elaborate integration of printed strain gauges, the application of piezo patch transducers was investigated by INVENT and FOOKE (Fig. 11). In order to detect three dimensional distortions and deformations of the z-slide, multiple piezo elements were mounted at the inside surface of the component. Since 4 piezo elements are applied at each wall of the slide, in total 16 piezo elements with 48 piezo ceramics are necessary. 
The piezo elements allow a highly sensitive detection of even small bending stresses in multiple directions. The functionality of theses sensors was analyzed at the realized prototype z-slide (see Sect. 9).

\section{Investigation of hollow sphere composite filling (Variant 2)}

In order to find a suitable approach for improving the structural damping of Variant 2 by a filling with hollow sphere composites (HSC), at first, fundamental investigations and simulations were conducted by the IFQ. For the FE simulation of the dynamic properties of different variations of filled slide components, the identification of material parameters - and especially the damping coefficients—is essential.
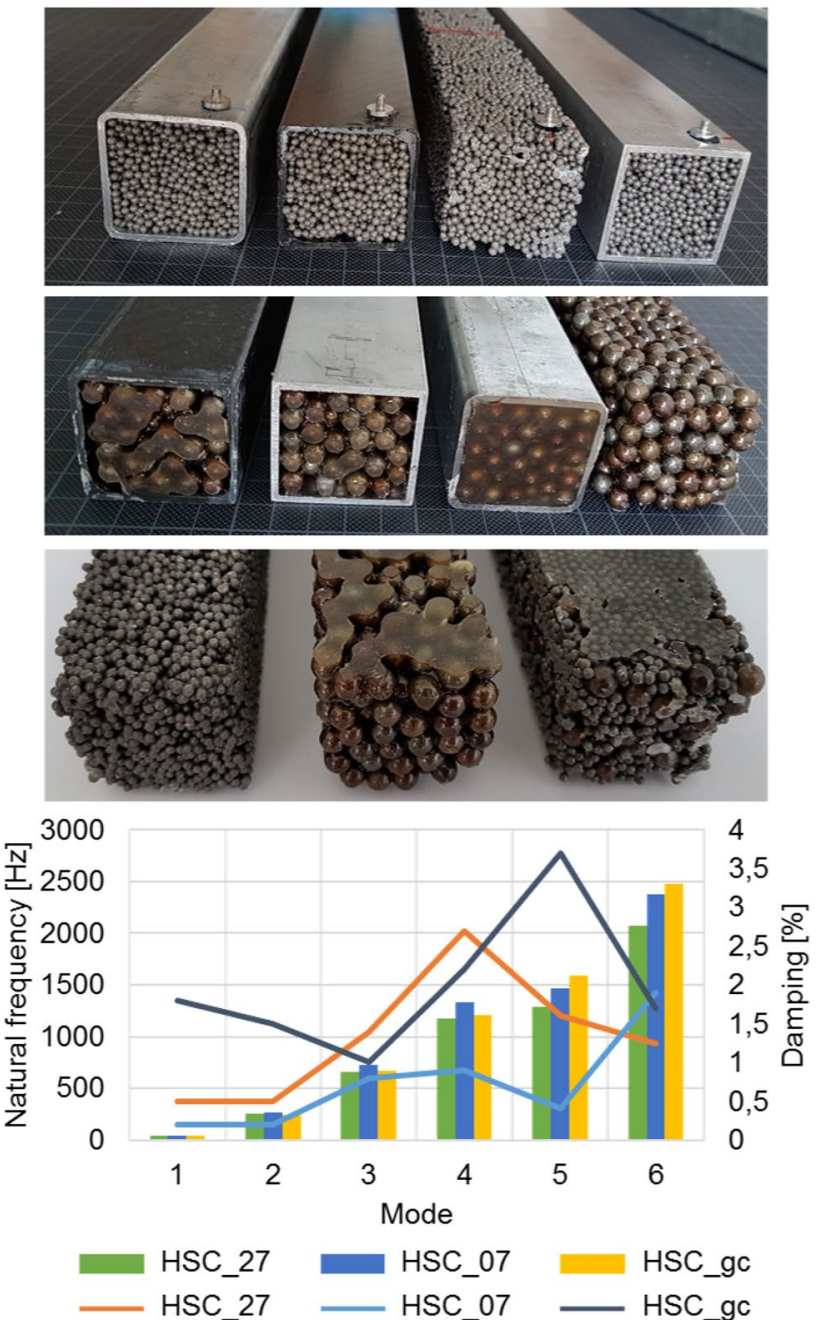

Fig. 12 Fundamental investigation of hollow sphere composite material properties (HSC_27: HSC with $2.7 \mathrm{~mm}$ spheres, HSC_07: HSC with $7 \mathrm{~mm}$ spheres, HSC_gc: grading curve with $2.7 \mathrm{~mm}$ and $7 \mathrm{~mm}$ spheres)
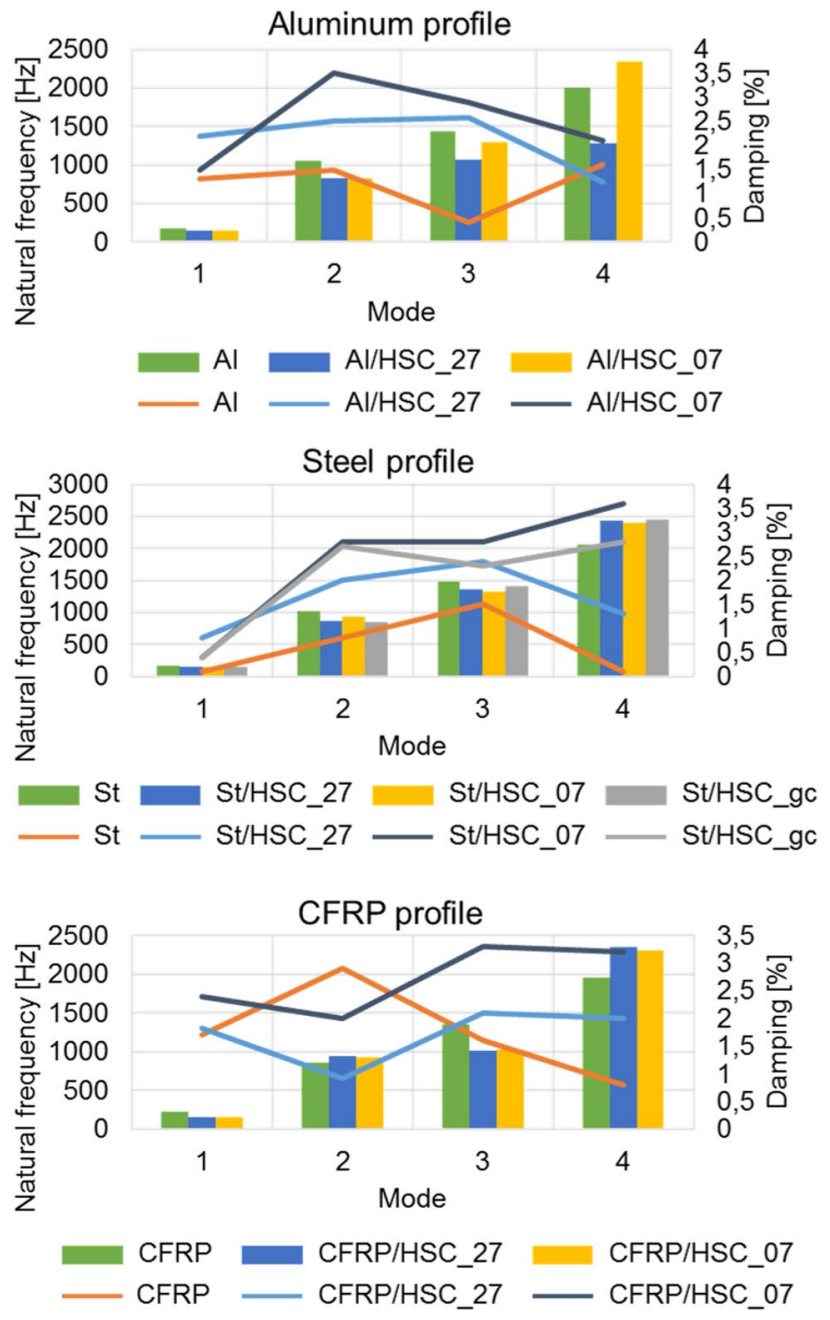

Fig. 13 Fundamental investigation of aluminum, steel and CFRP profiles filled with HSC

In this respect, several test specimen consisting purely of HSC with different diameters of the spheres and combining HSCs with metal and CFRP profiles were analyzed experimentally. The diameter variation of the spheres was limited to $2.7 \mathrm{~mm}, 7 \mathrm{~mm}$ and a grading curve mixture of these. The grading curve consists of $50.1 \%$ of $2.7 \mathrm{~mm}$ spheres and $49.9 \%$ of $7 \mathrm{~mm}$ spheres. For modal analyses, test specimen with a length of $500 \mathrm{~mm}$ and $40 \mathrm{~mm}$ length of edges were produced. Figure 12 shows some specimen and measurement results for the pure HSC specimen. In Fig. 13, test results

Table 2 Material parameters of analyzed hollow sphere composites

\begin{tabular}{lllll}
\hline & $\alpha\left[\mathrm{s}^{-1}\right]$ & $\beta[\mathrm{s}]$ & $\mathrm{E}[\mathrm{MPa}]$ & $\rho\left[\mathrm{kg} / \mathrm{m}^{3}\right]$ \\
\hline $2.7 \mathrm{~mm}$ & 7.85 & $3.18 \mathrm{E}-6$ & 27,800 & 440 \\
$7 \mathrm{~mm}$ & 3.29 & $1.21 \mathrm{E}-6$ & 34,700 & 500 \\
Grading curve & 9.76 & $3.98 \mathrm{E}-6$ & 54,365 & 470.06 \\
\hline
\end{tabular}


Table 3 Simulation results of different fillings for Variant 2

\begin{tabular}{|c|c|c|c|c|c|c|c|c|c|}
\hline \multirow{2}{*}{ Variant } & \multirow{2}{*}{ Filling } & \multicolumn{3}{|c|}{$\begin{array}{c}\text { 1. Bending mode in x- } \\
\text { direction }\end{array}$} & \multicolumn{3}{c|}{$\begin{array}{c}\text { 1. Bending mode in y- } \\
\text { direction }\end{array}$} \\
\cline { 3 - 10 } & & $\begin{array}{c}\text { Frequency } \\
{[\mathrm{Hz}]}\end{array}$ & $\begin{array}{c}\text { Damping } \\
\text { [\%] }\end{array}$ & $\begin{array}{c}\text { Frequency } \\
\text { [Hz] }\end{array}$ & \multicolumn{2}{c|}{$\begin{array}{c}\text { Damping } \\
{[\%]}\end{array}$} \\
\hline $\begin{array}{c}\text { without } \\
\text { filling }\end{array}$ & $(0 / 0 / 0)$ & 34.2 & & 0.09 & & 40.6 & & 0.07 & \\
\hline HSC $2.7 \mathrm{~mm}$ & $(1 / 0 / 0)$ & 34.3 & $0 \%$ & 0.10 & $14 \%$ & 40.8 & $1 \%$ & 0.08 & $13 \%$ \\
\hline HSC $2.7 \mathrm{~mm}$ & $(1 / 1 / 0)$ & 35.2 & $3 \%$ & 0.10 & $15 \%$ & 41.9 & $3 \%$ & 0.08 & $15 \%$ \\
\hline HSC $2.7 \mathrm{~mm}$ & $(1 / 1 / 1)$ & 36.8 & $8 \%$ & 0.10 & $12 \%$ & 43.0 & $6 \%$ & 0.08 & $13 \%$ \\
\hline HSC 7mm & $(1 / 0 / 0)$ & 34.4 & $0 \%$ & 0.09 & $6 \%$ & 40.8 & $1 \%$ & 0.08 & $6 \%$ \\
\hline HSC 7mm & $(1 / 1 / 0)$ & 35.3 & $3 \%$ & 0.09 & $5 \%$ & 42.1 & $4 \%$ & 0.07 & $4 \%$ \\
\hline HSC 7mm & $(1 / 1 / 1)$ & 37.2 & $9 \%$ & 0.09 & $0 \%$ & 43.3 & $7 \%$ & 0.07 & $1 \%$ \\
\hline HSC g.c. & $(1 / 0 / 0)$ & 34.4 & $1 \%$ & 0.11 & $18 \%$ & 41.0 & $1 \%$ & 0.09 & $18 \%$ \\
\hline HSC g.c. & $(1 / 1 / 0)$ & 35.7 & $4 \%$ & 0.11 & $20 \%$ & 42.6 & $5 \%$ & 0.09 & $20 \%$ \\
\hline HSC g.c. & $(1 / 1 / 1)$ & 38.0 & $11 \%$ & 0.10 & $16 \%$ & 44.3 & $9 \%$ & 0.09 & $19 \%$ \\
\hline
\end{tabular}

for filled specimen are presented. The specimen with the grading curve provide the highest damping.

Based on these experiments, material parameters and damping coefficients for the FE simulation of the filled $\mathrm{z}$-slide were derived by comparison of tested and simulated specimen. The resulting values are summarized in Table 2.

By means of these material parameters, the dynamic properties of the Variant 2 z-slide were calculated with FE models. Three types of fillings were considered (Fig. 4). Table 3 contains the related results.

The filling with HSC with $2.7 \mathrm{~mm}$ spheres shows higher damping than that with $7 \mathrm{~mm}$ spheres. The best damping properties are provided by the grading curve. Because of the dominant first vibration mode (bending of the $\mathrm{z}$-slide relative to the cross slide), a filling of only the lowermost chamber provides the best compromise between the advantageous increase of damping and the disadvantageous increase of mass by the composite.

\section{Analysis of the influence of coolant lubricant and damages of the CFRP}

Since the CFRP elements of the newly designed z-slides are exposed to coolant lubricant and chips during the machining processes, an important question is, whether the influences of these conditions affect the structural behavior, elasticity and strength of the machine component. Therefore, fundamental investigations were carried out by the IFQ in order to identify effects of coolant lubricant on intact and partly damaged CFRP specimen. For the analyses, CFRP plates $(112 \mathrm{~mm} \times 450 \mathrm{~mm} \times 2.4 \mathrm{~mm})$ were used in certain
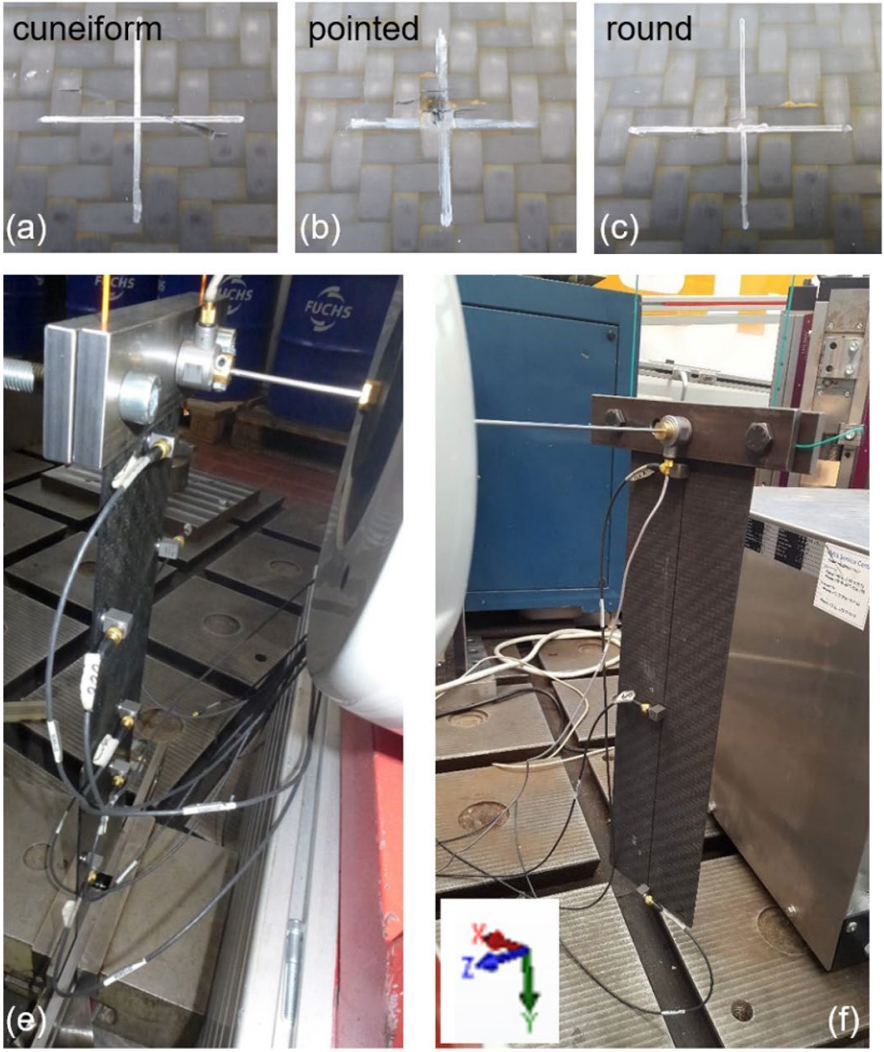

(d)
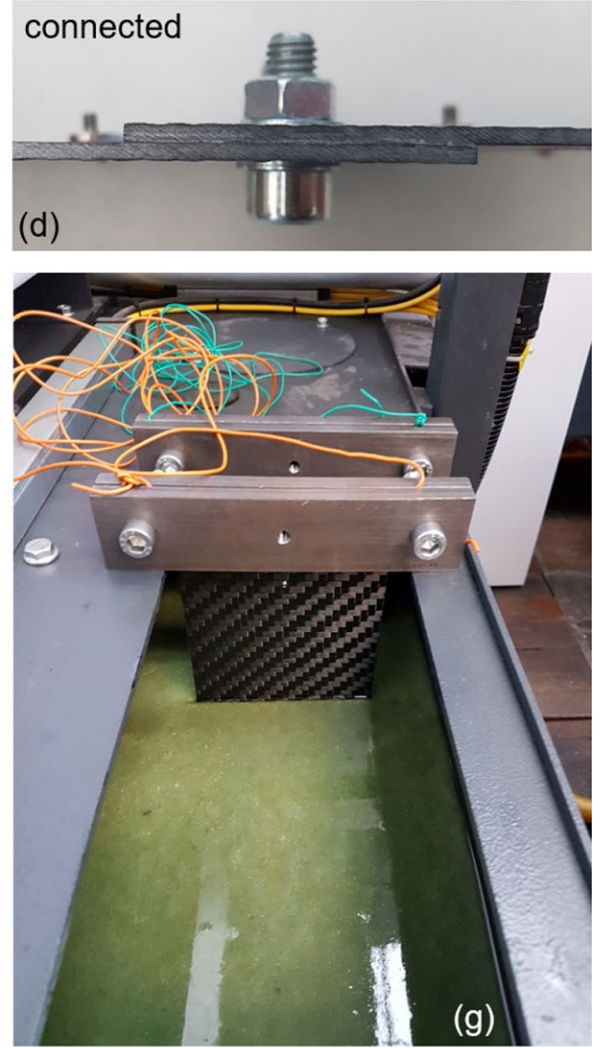

Fig. 14 Fundamental investigation of influences by coolant lubricant 

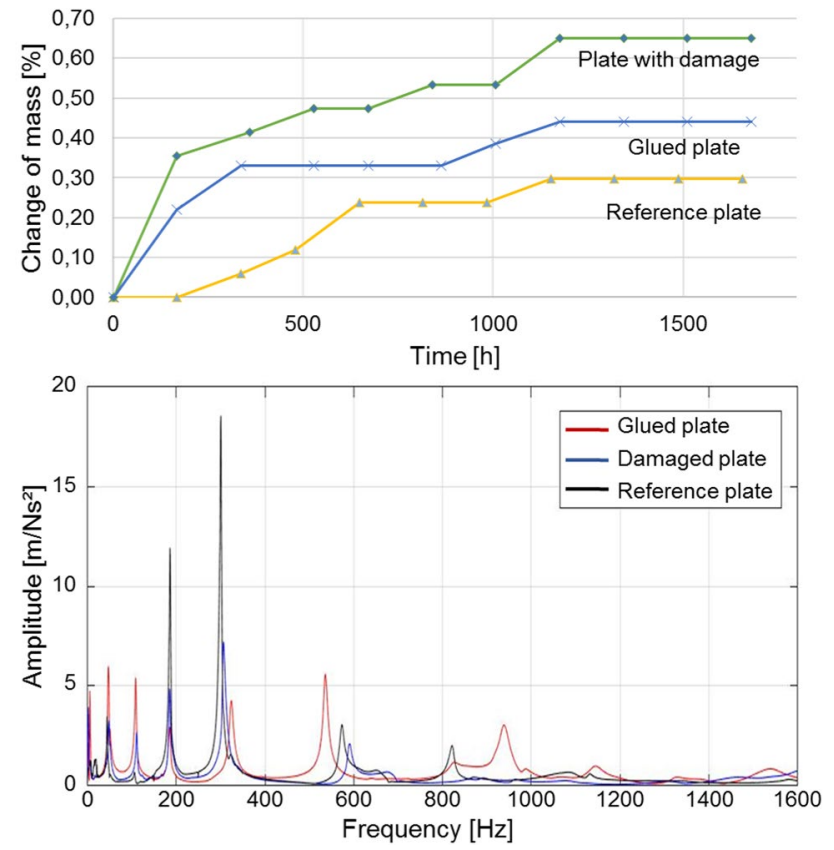

Fig. 15 Change of mass and frequency response of test plates affected by coolant

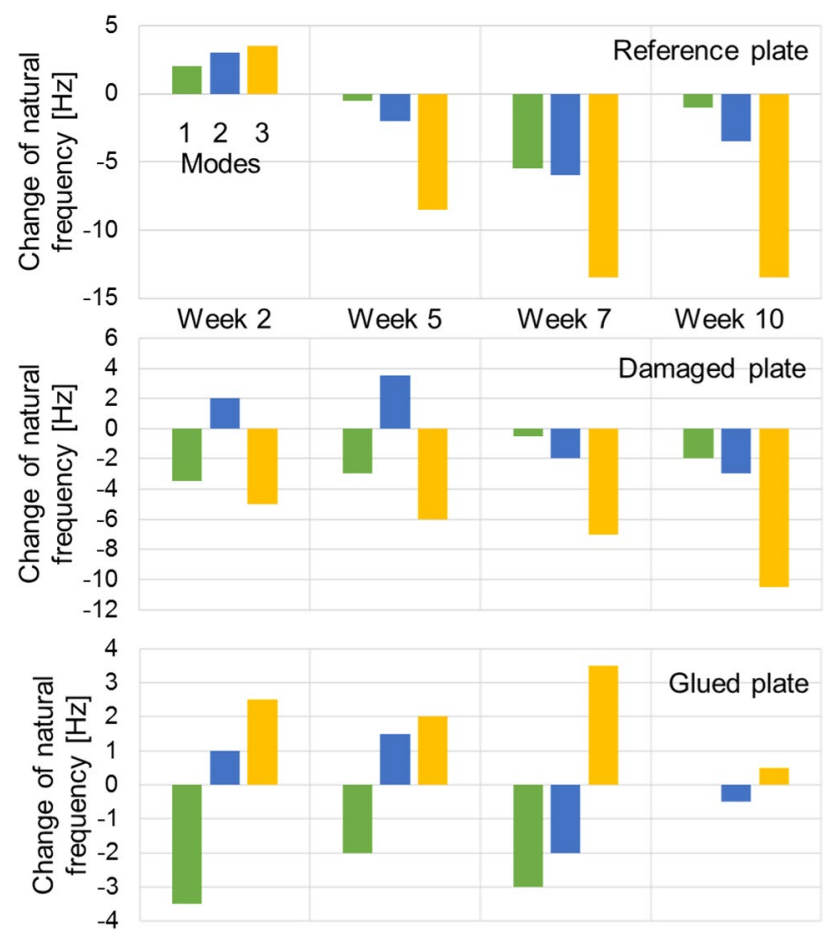

Fig. 16 Change of natural frequencies of test plates affected by coolant

variations: with/without Teflon foil, biased by a 3-point bending test and damaged by an impact with cuniform, pointed and round bodies (Fig. 14a-c). Furthermore, plates connected by screwing, gluing, as well as screwing and gluing were considered (Fig. 14d). The test plates were connected to a horizontal vibrating shaker by an adapter at the top of the specimen. The lower end was either clamped (Fig. 14e) or free (Fig. 14f). By means of the adapter, the test plates could be hanged into a tank filled with coolant lubricant (Fig. 14g). In order to investigate the influence of the coolant penetration, the test plates were excited by the shaker and the vibration modes of the plates were analyzed. These tests were conducted repeatedly after several coolant penetration cycles. In addition, the change of the weight of the specimen was observed in order to identify moisture absorption.

Figures 15 and 16 show the results of the tests and the influence of the coolant lubricant becomes visible. However, the absolute values of the changes of mass and natural frequencies are relatively low. Regarding the weight measurements, an uncertainty of the measuring system has to be considered, so that the recognized changes of the mass must be validated in future. Also, a long term study of the influences which exceeds 10 weeks significantly is necessary to identify effects relevant for industrial application. For this, a special test rig was designed and built, that will be used in future investigations.

\section{Realization of slide component prototypes}

Following the design and optimization, the approaches of new lightweight z-slides were realized (Figs. 17, 18). Regarding Variant 1 (Fig. 17), at first, the CFRP parts were manufactured by INVENT. For this, a specific mold (1) was produced and provided by FOOKE. The CFRP fabrics were cut (2) and placed on the mold (3) according to the fiber orientations of each layer resulting from the optimization. After infiltration (4) and curing, the raw CFRP half shells (5) were further processed ( 6 and 7 ) by machining by FOOKE. Inserts (8) were used for screwing (9) the steel bars (10) at the edges of the half shells. Furthermore, the parallel produced piezo patch transducers were mounted at the inside of the half shells (11) and connected with flat cables (12) by INVENT. After ensuring the mounting tolerances (13), the internal frames and center tubing were glued into one of the half shells (14). Subsequently, the half shells were combined and glued together (15). The metallic interfaces at the edges and the inserted connector plate to the machining head were machined by FOOKE (16) in order to ensure the required geometric accuracy of the overall slide component (17). The body of the z-slide was coated by clear varnish and mounted into a standard ENDURA $® 711$ Linear machine tool instead of the conventional slide. This allowed intensive 

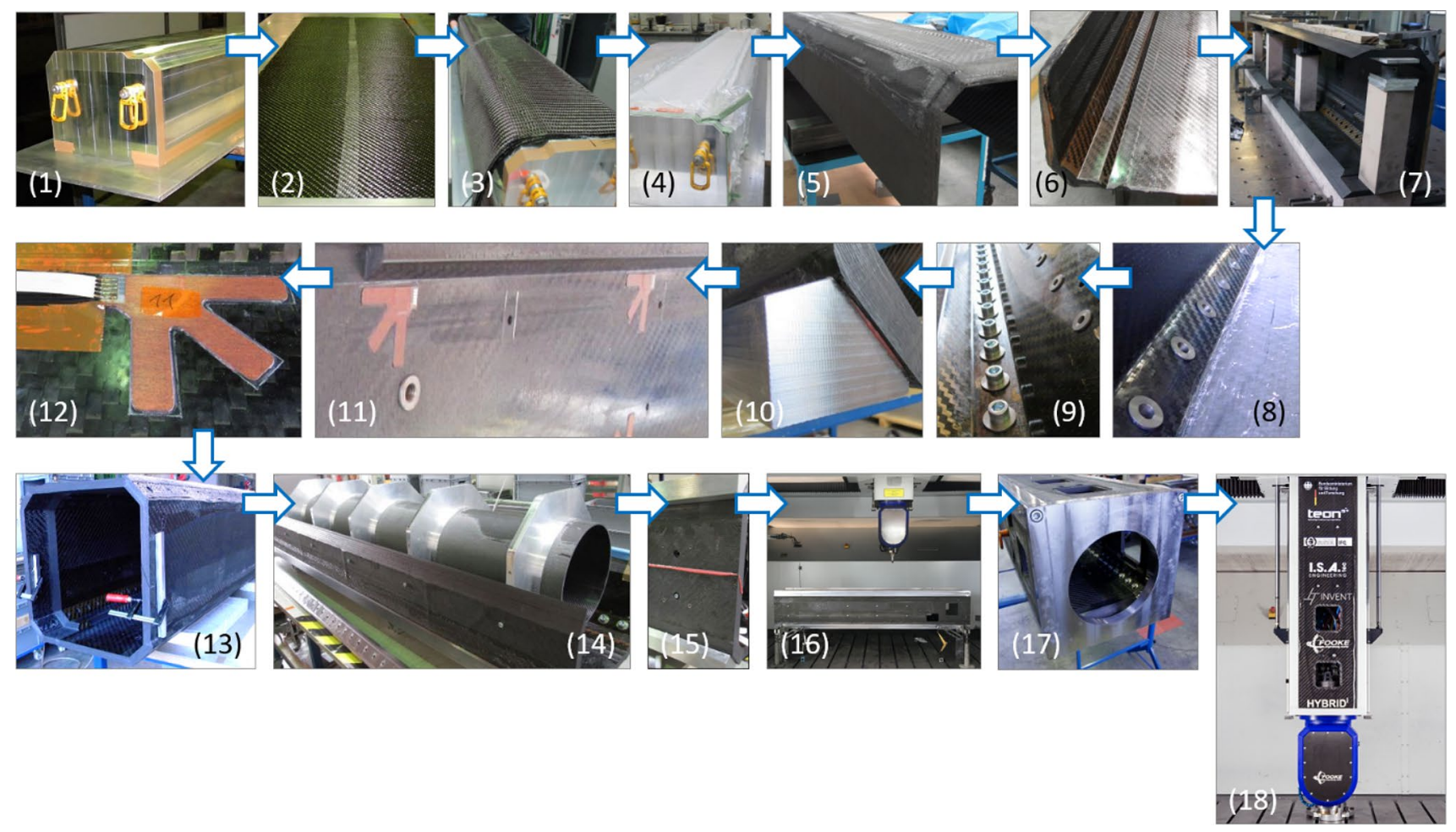

Fig. 17 Realization of Variant 1
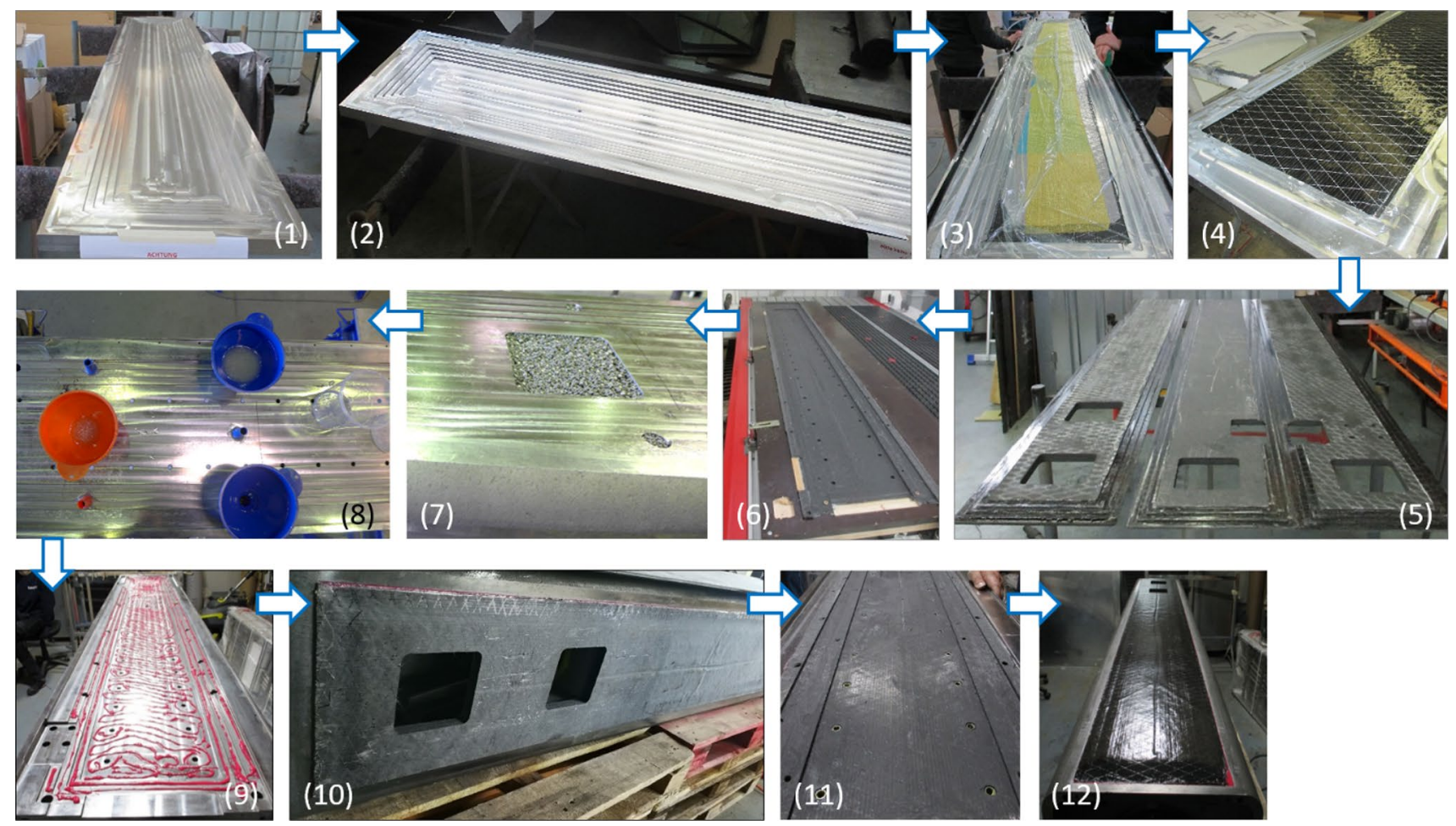

Fig. 18 Realization of Variant 2 
investigations of the new slide component in experiments and machining tests (see Sect. 8).

The realization of Variant 2 is depicted in Fig. 18. This was implemented predominantly by TEON. Based on the optimization of the CFRP layer buildup (Sect. 3), the individual plates of Variant 2 were realized by means of a specific mold (1 and 2). In order to achieve the wall thickness of $17 \mathrm{~mm}$, the manufacturing was implemented in four parts. With respect to the stepped geometry of the plates, each step was produced consecutively by infusion (3 and 4). In order to optimize the bonding between each partition, the manufacturing process was adjusted so that a previously produced step was not cured completely before the next step is infused. This procedure, the penetration of the fiber layers by the matrix material, the wetting of the fibers, as well as the curing and bonding were first analyzed with test specimen. The consolidated CFRP elements (5) were machined (6) in order to achieve the necessary accuracy for the integration into the skeleton of the casted slide. Considering the results of the fundamental analyses of HSC (see Sect. 5), one chamber inside the slide structure was filled with hollow spheres (7) and resin (8). Subsequently, the CFRP elements were glued into the pockets inside the walls of the slide (9 and 10). For the mounting of linear guides and the secondary part of the linear drive, inserts were integrated (11). As a result, also Variant 2 was realized in real dimension (12) and is available for further tests and experiments.

\section{Evaluation of the machine tool characteristics with integrated prototype (Variant 1)}

The evaluation of the integrated Variant $1 \mathrm{z}$-slide included the analysis of the static stiffness, dynamic response (in terms of modal analyses), thermal stability, and the measurement of the overshoot in dynamic positioning tests. Finally, machining tests were implemented and the surface of the machined test work pieces was assessed. The measurement results obtained with the new slide prototype were compared to previous experiments with the conventional slide. The static stiffness and dynamic response were analyzed at different positions of the TCP in order to consider influences of the kinematic conditions. The results of the investigation of the static stiffness are presented in Fig. 19 (the total values cannot be presented due to confidentiality). In the measurements, static loads up to a force of $600 \mathrm{~N}$ were applied in repeated cycles and positive as well as negative directions ( $\mathrm{x}$ and $\mathrm{y}$ ). Figure 19 shows the mean values of the individual experiments. As can be seen, the CFRP slide provides lower stiffness values than the conventional slide. This effect could not be avoided completely during the design and optimization. However, since the major goal of Variant 1 was the
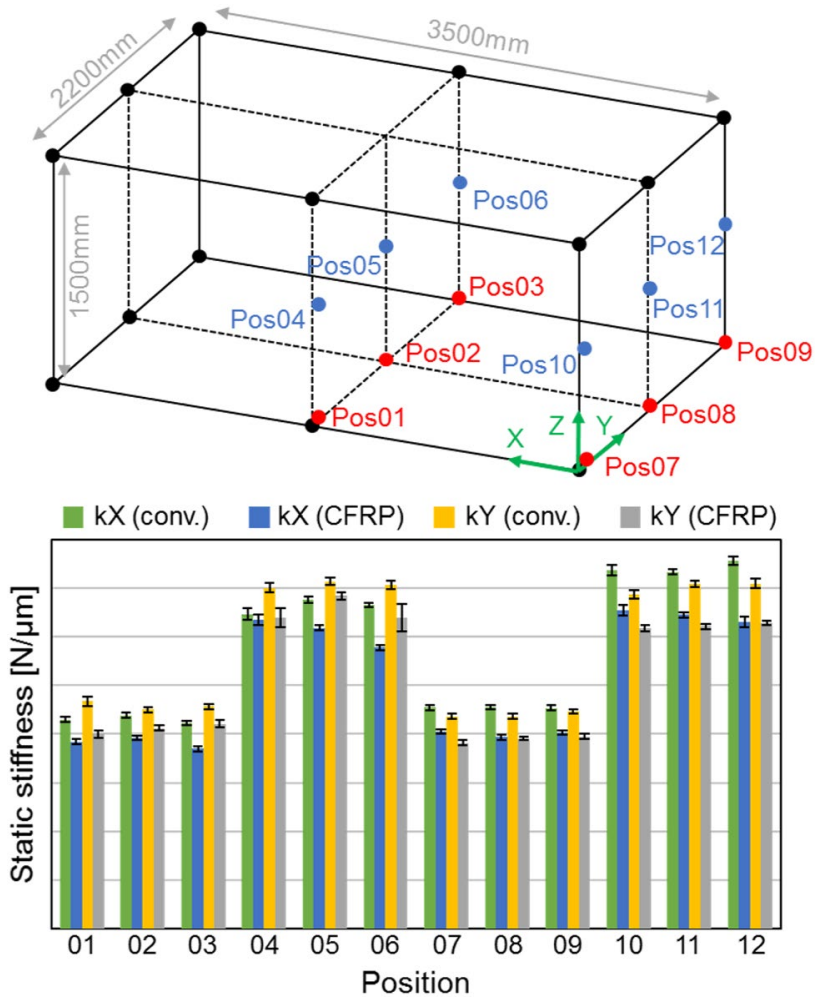

Fig. 19 Comparison of the static stiffness

reduction of the mass and the stiffness values remain within an acceptable range, the results are satisfactory.

During the modal analyses, all feed axes (X, Y, Z, A, C) were clamped. The dynamic response of the slide components (conventional and new CFRP) was gathered by means of 9 tri-axial acceleration sensors which were mounted at distributed positions at the slides (Fig. 20). The excitation was implemented with a modal testing hammer at "moving" positions. Thus, a frequency range of up to $400 \mathrm{~Hz}$ was covered with a resolution of $1 \mathrm{~Hz}$. The measured frequency response functions were averaged in order to derive characteristic values for the natural frequencies of the first four vibration modes and the related damping (Fig. 20). The first mode is a bending in $\mathrm{x}$-direction and the second mode is a bending in y-direction, as expected. The third mode is a torsional vibration about the $\mathrm{z}$-axis and the fourth mode is the second bending mode in y-direction. As can be seen, the natural frequencies of the CFRP slide are comparable or higher than those of the conventional casted slide. The damping differs depending on the position and the vibration mode. Especially the torsional mode is influenced positively by the new structure.

In order to analyze the thermal behavior, the center position (Pos02 in Fig. 19) was regarded. The workspace of the machine tools was heated up by means of distributed fan 
Fig. 20 Comparison of the dynamic response

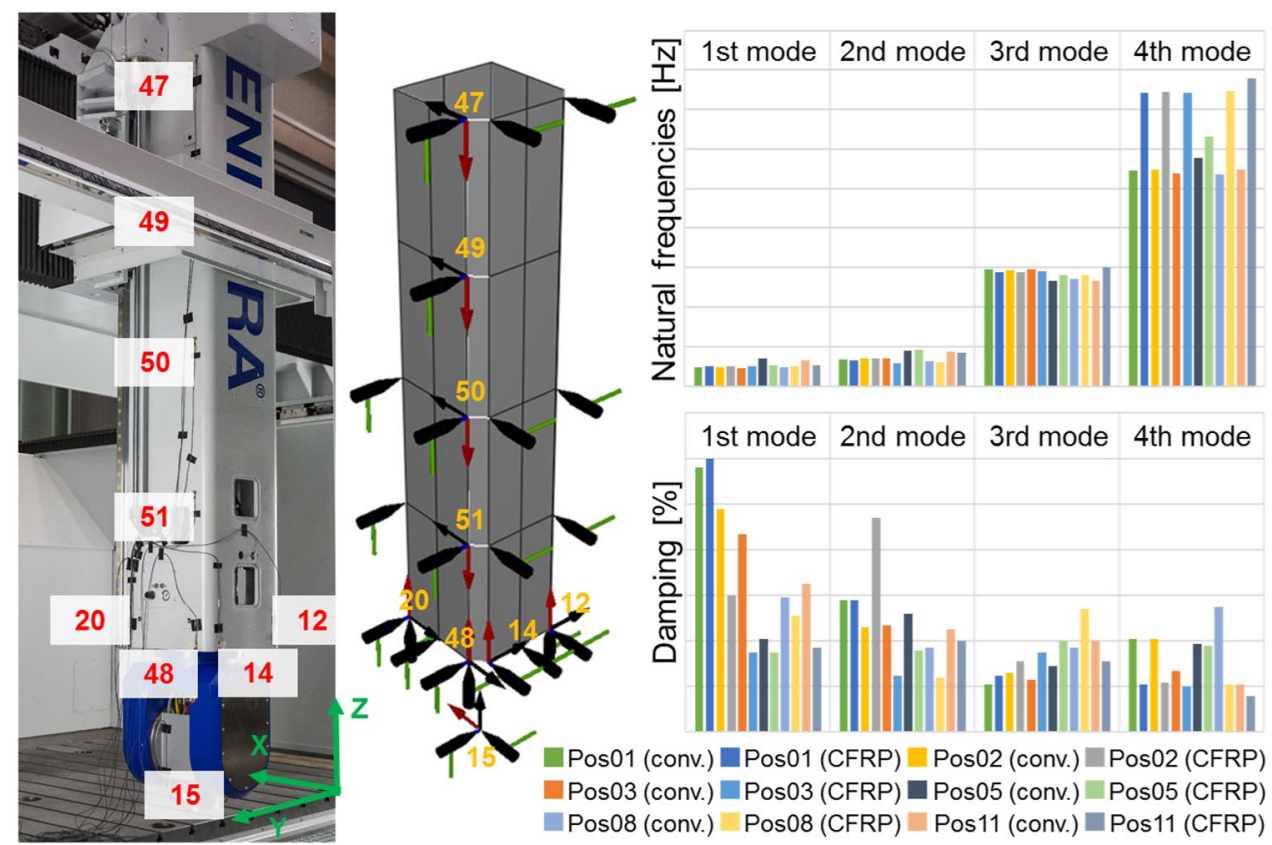

heaters. The thermal induced displacements were measured by inductive gauges at the TCP. Figure 21 shows results of temperatures and displacements for both the conventional casted and the new CFRP-slide when applying different external heating conditions. The displacements of the conventional slide for external heating of the rear surface are taken as a reference and therefore marked in red (the absolute values cannot be published due to confidentiality).

In addition to the external heating, the effects of fast accelerations of the feed axes were investigated. For this, a linear motion of the $\mathrm{z}$-axis $\left(\mathrm{v}_{\mathrm{f}}=25 \mathrm{~m} / \mathrm{min}\right.$ and $\left.40 \mathrm{~m} / \mathrm{min}\right)$ and a V-shaped path in the $\mathrm{x}-\mathrm{y}$-plane $\left(\mathrm{v}_{\mathrm{f}}=30 \mathrm{~m} / \mathrm{min}\right.$ and $53 \mathrm{~m} / \mathrm{min}$ ) were implemented. The linear feed motion was carried out repeatedly for $30 \mathrm{~min}$ with $300 \mathrm{~mm}$ length of the path, followed by the measuring of the displacements. The overall heating time was $5 \mathrm{~h}$ and a quasi-stationary thermal state was achieved. Subsequently, the cooling phase was also observed with respect to the decline of the TCP deviations. Analogously, the V-shaped path was implemented during an overall measuring time of $8 \mathrm{~h}$ and a path length of $300 \mathrm{~mm}$ was applied. During the tests, the temperatures were gathered at distributed positions at the machine structure. In addition, the ambient temperature was recorded.

The results of the thermal displacements for the different thermal load conditions are summarized in Fig. 22. As can be seen, a significant reduction of the thermal displacements is achieved with the new slide construction.

The overshoot in $\mathrm{x}-, \mathrm{y}$ - and $\mathrm{z}$-direction was measured by 3 eddy current sensors at the TCP. Two parameter settings ("rough" and "exact") in terms of max. acceleration and jerk were assessed $\left(a_{\max }=2.8\right.$ and $1.75 \mathrm{~m} / \mathrm{s}^{2} ; \mathrm{j}_{\max }=40$ and $10 \mathrm{~m} /$ $\mathrm{s}^{3}$ ) and feed velocities of $\mathrm{v}_{\mathrm{f}}=10,30$ and $50 \mathrm{~m} / \mathrm{min}$ were applied. It was found that even with the settings "rough" and $\mathrm{v}_{\mathrm{f}}=50 \mathrm{~m} / \mathrm{min}$ an overshoot of $22 \mu \mathrm{m}$ in $\mathrm{x}$ - and $3 \mu \mathrm{m}$ in $\mathrm{y}$-direction could be achieved, where values below $30 \mu \mathrm{m}$ can be rated as "good" for this type of machine tools.

Finally, machining tests were carried out in terms of milling a test work piece (Fig. 23). The complex geometry contains various surfaces and profiles with high demands on the precision and dynamic performance of the feed axes. In Fig. 23, the surface quality of the face on the right hand side of the test workpiece is assessed. Two parameter settings in terms of the jerk were analyzed. Figure 24 shows the projected surface area of the specimen as a result of the machining tests. As a conclusion, an acceptable surface quality was achieved. The increase of the jerk parameter does not lead to a drastic increase of the profile depth and roughness values bus allow time savings of more than $10 \%$. Figure 25 shows the surface structures at the peak of the workpiece resulting from machining. The surface milled with the conventional slide shows some structures that suggest a minimal vibration that settles after the change of the feed direction. In contrast, this surface structure cannot be found in the milling results with the CFRP-slide and the chosen control parameters. This shows, that with the lightweight machine component an improved surface quality can be achieved especially at workpiece geometries where a fast change of the feed motion is necessary. 

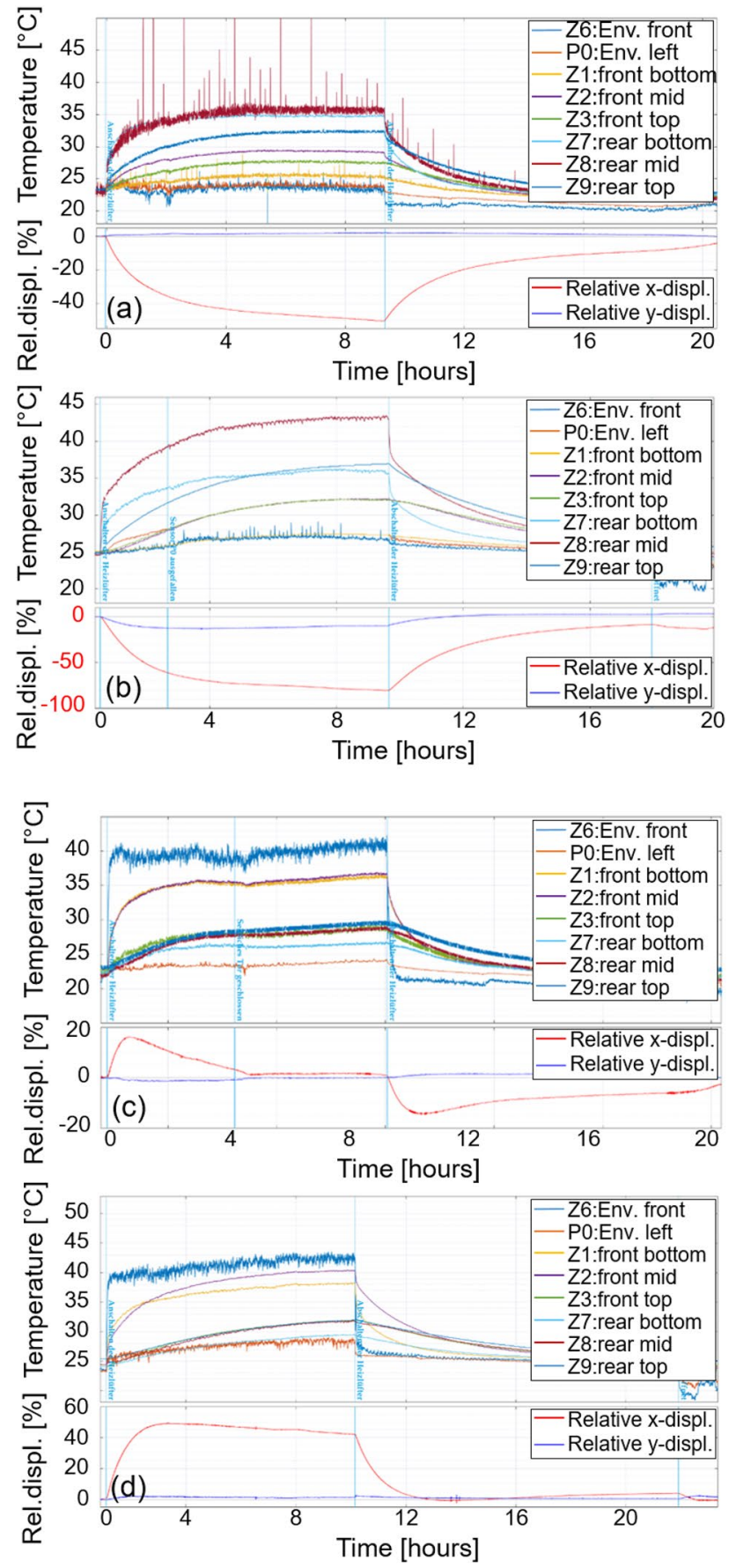

Fig. 21 Temperatures and displacements of Z-slide variants applying external heating: a external heating of rear surface of CFRP-slide, $\mathbf{b}$ external heating of rear surface of casted slide being the reference, $\mathbf{c}$ external heating of front surface of CFRP-slide, $\mathbf{d}$ external heating of front surface of casted slide

\section{Analysis of integrated sensors (Variant 1)}

With respect to the functionality and sensitivity of the integrated piezo patch transducers, the signals of these sensors were recorded during the analyses of the overshoot (see

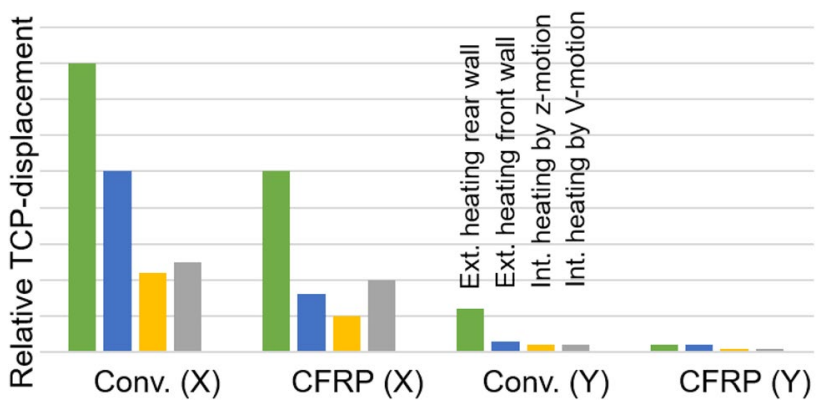

Fig. 22 Comparison of thermal displacements for different load conditions

Sect. 8). Figure 26 shows the voltages of two parts of the tripartite sensor structure that is mounted at middle height of the $\mathrm{z}$-slide. The signals were acquired during a motion with parameter settings "rough" and $\mathrm{v}_{\mathrm{f}}=10 \mathrm{~m} / \mathrm{min}$. The high sensitivity and, thus, the capability to monitor the structural behavior during machine operation becomes obvious. Further investigations regarding the utilization of the integrated sensors with respect to process control are necessary.

\section{Summary, conclusion and outlook}

This paper presents the development, realization and analyses of two variants of newly designed lightweight machine tool slide components with integrated sensors. One variant was optimized with respect to a maximum mass reduction. The second variant was optimized with respect to its static stiffness and the manufacturing cost. Since the realized prototypic slide components were manufactured manually in single piece production, the related cost cannot be taken as the final production cost in an industrial environment. Within the research project, the prototypic Variant 1 appeared to be approximately 10 times as expensive as the conventional casted slide, whereas the prototypic Variant 2 was approximately 4.5 times as expensive as the casted slide. Measures to reduce these cost will be investigated in future.

Compared to the conventional casted slide, a mass reduction by $52 \%$ (Variant 1) could be achieved. Even with the stiffness-optimized slide (Variant 2) a mass reduction by approx. 30\% was calculated. The lightweight-optimized prototype (Variant 1) showed a slightly lower static stiffness than the conventional slide. The dynamic response possessed comparable or increased first natural frequencies and, depending on the slide position and vibration mode, a higher damping. In order to increase the damping properties of the stiffness-optimized slide (Variant 2), a filling with hollow sphere composites was investigated that led to an increase of damping of up to $15 \%$ or $20 \%$, depending on the type 
Fig. 23 Results of machining tests with different values of mass (m), jerk (J), acceleration (a), feed velocity $\left(v_{f}\right)$ and time $(\mathrm{t})$
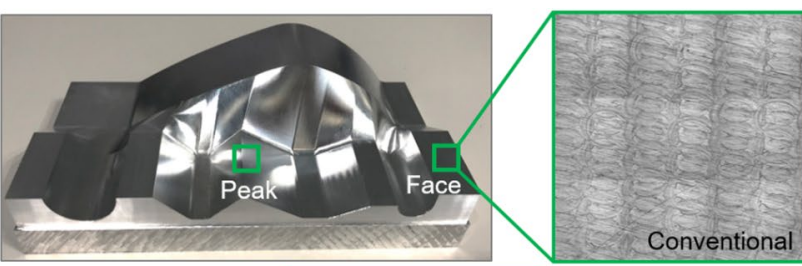

\begin{tabular}{|l|l|l|l|}
\hline$[\%]$ & Conv. & CFRP_1 & CFRP_2 \\
\hline $\mathrm{m}$ & 100 & 51,7 & 51,7 \\
\hline $\mathrm{J}$ & 100 & 100,0 & 166,7 \\
\hline $\mathrm{a}$ & 100 & 100,0 & 100,0 \\
\hline $\mathrm{v}_{\mathrm{f}}$ & 100 & 100,0 & 100,0 \\
\hline $\mathrm{t}$ & 100 & 100,0 & 88,7 \\
\hline
\end{tabular}
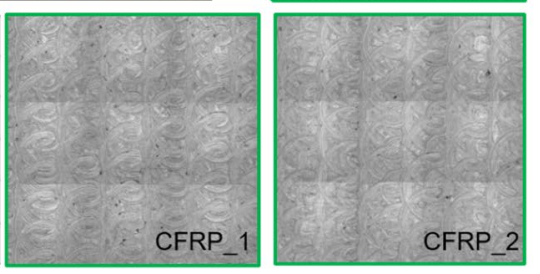

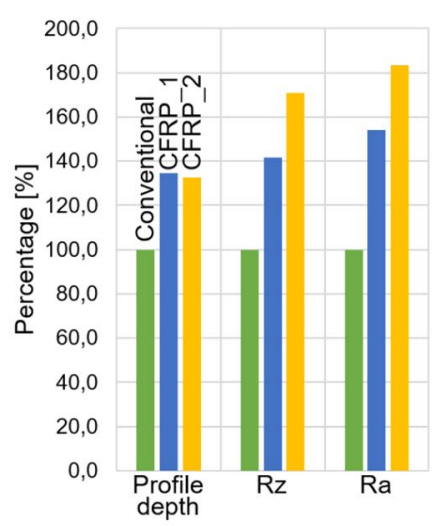

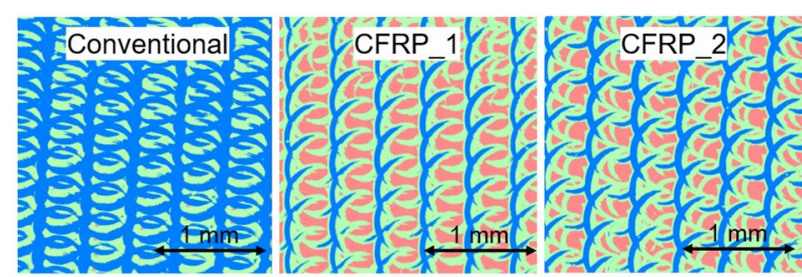

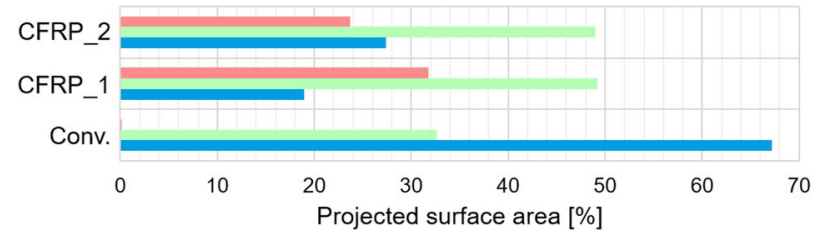

Fig. 24 Projected surface areas obtained in machining tests of the filling material composition. Due to the significantly higher thermal stability, the accuracy of the machine tool with integrated CFRP-slide (Variant 1) could be improved. Machining tests revealed that an acceptable or even better surface quality can be achieved with the integrated CFRPslide. A positive side effect is that the energy consumption of the feed drives during feed motion and machining could be reduced by up to $10 \%$. Besides the advantageous technical characteristics, these energy savings contribute to the amortization of the comparably higher invest into the innovative hybrid structures with CFRP elements. In this regard it has to be pointed out, that by means of the lightweight CFRP-slide (Variant 1) the control settings with respect
Fig. 25 Surface structures at the peak of the workpiece resulting from machining
Fig. 26 Sensitivity of the integrated piezo sensors

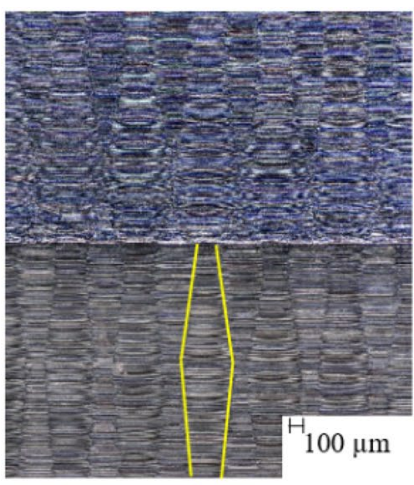

Conventional

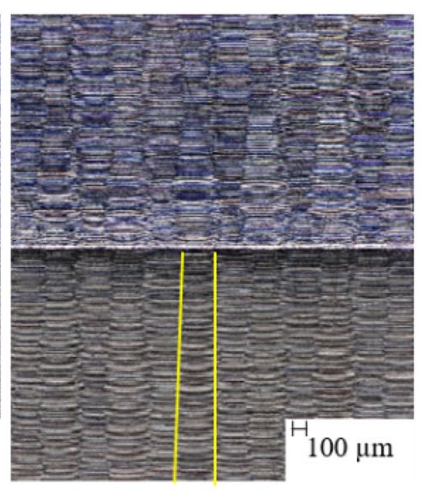

CFRP_1

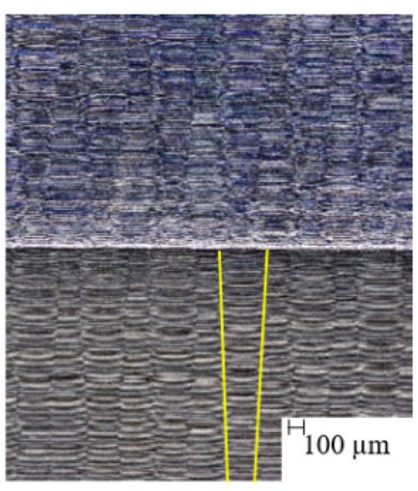

CFRP_2
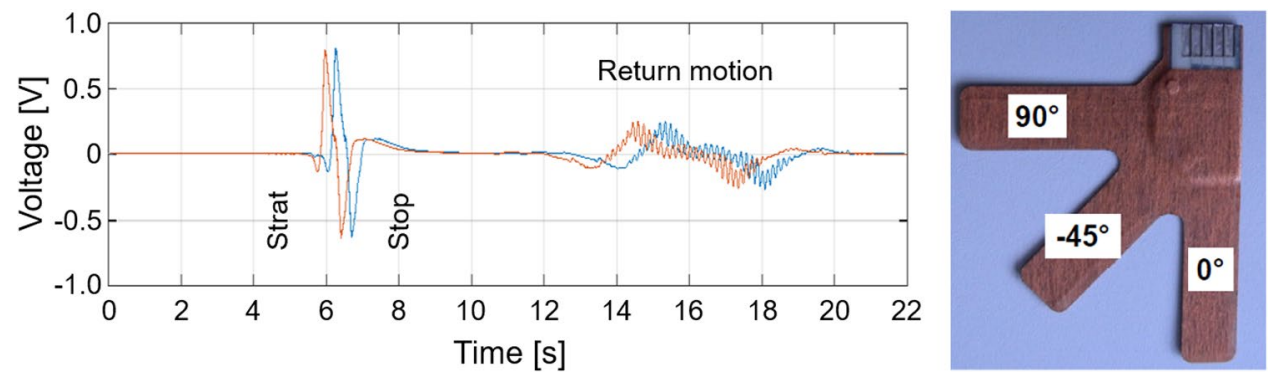
to acceleration and jerk limits could be increased. Consequently, a higher path dynamics and considerably shorter machining times can be achieved.

Acknowledgement The HYBRID ${ }^{\mathrm{i}}$ joint research project was kindly funded by the German Federal Ministry of Education and Research (BMBF) within the "Innovations for Tomorrow's Production, Services and Work" Program (funding number 02P14A110 - 02P14A114) and implemented by the Project ManagementAgency Karlsruhe (PTKA). The project was coordinated by the company FOOKE as well as supervised and supported by the PTKA.

Funding Open Access funding enabled and organized by Projekt DEAL.

Open Access This article is licensed under a Creative Commons Attribution 4.0 International License, which permits use, sharing, adaptation, distribution and reproduction in any medium or format, as long as you give appropriate credit to the original author(s) and the source, provide a link to the Creative Commons licence, and indicate if changes were made. The images or other third party material in this article are included in the article's Creative Commons licence, unless indicated otherwise in a credit line to the material. If material is not included in the article's Creative Commons licence and your intended use is not permitted by statutory regulation or exceeds the permitted use, you will need to obtain permission directly from the copyright holder. To view a copy of this licence, visit http://creativecommons.org/licenses/by/4.0/.

\section{References}

1. Gümüsdere G, Gerczynski M (ed) (2011) Study on competitiveness of the European machine tool industry. CECIMO, www. cecimo.eu

2. Möhring H-C, Brecher C, Abele E, Fleischer J, Bleicher F (2015) Materials in machine tool structures. CIRP Ann Manufact Technol 64(2015):725-748

3. Möhring H-C (2017) Composites in production machines. Procedia CIRP 66:2-9

4. Kroll L, Blau P, Wabner M, Frieß U, Eulitz J, Klärner M (2011) Lightweight components for energy-efficient machine tools. CIRP J Manuf Sci Technol 4:148-160

5. Jung SC, Lee JE, Chang SH (2004) Design of inspecting machine for next generation LCD glass panel with high modulus carbon/ epoxy composites. Compos Struct 66:439-447

6. Lee CS, Oh JH, Lee DG, Choi JH (2001) A composite cantilever arm for guiding a moving wire in an electrical discharge wire cutting machine. J Mater Process Technol 113:172-177

7. Chang SH, Kim PJ, Lee DG, Choi JK (2001) Steel-composite hybrid headstock for high-precision grinding machines. Compos Struct 53:1-8

8. Suh JD, Lee DG (2002) Composite machine tool structures for high speed milling machines. Ann CIRP 51(1):285-288

9. Lee DG, Suh JD, Kim HS, Kim JM (2004) Design and manufacture of composite high speed machine tool structures. Compos Sci Technol 64:1523-1530

10. Suh JD, Lee DG (2004) Thermal characteristics of composite sandwich structures for machine tool moving body applications. Compos Struct 66:429-438

11. Kim J-H, Chang S-H (2010) Design of $\mu-C N C$ machining centre with carbon/epoxy composite-aluminium hybrid structures containing friction layers for high damping capacity. Compos Struct 92:2128-2136
12. Lee DG, Chang SH, Kim HS (1998) Damping improvement of machine tool columns with polymer matrix fiber composite material. Compos Struct 43:155-163

13. Smolik J, Kulisek V (2009) Application of unconventional materials on primary structural parts of machine tools. J Mach Eng 9(2):93-105

14. Kim DI, Jung SC, Lee JE, Chang SH (2006) Parametric study on design of composite-foam-resin concrete sandwich structures for precision machine tool structures. Compos Struct 75:408-414

15. Kulisek V, Janota M, Ruzicka M, Vrba P (2013) Application of fibre composites in a spindle ram design. J Mach Eng 13(1):7-23

16. Fleischer J, Bauer J, Koch S-F, Wagner H (2013) CFK als "Enabler" im Werkzeugmaschinenbau, VDI-Z 155. Nr 7(8):74-76

17. Koch S-F, Bauer J, Horsch J, Wagner H, Fleischer J (2013) Maschinenkomponenten mit adaptierbarer Eigenfrequenz. ZWF 108(7-8):1-5

18. Kim HS, Park SW, Lee DG (2006) Smart cure cycle with cooling and reheating for co-cure bonded steel/carbon epoxy composite hybrid structures for reducing thermal residual stress. Compos Part A 37:1708-1721

19. Lee CS, Lee DG, Oh JH (2004) Co-cure bonding method for foam core composite sandwich manufacturing. Compos Struct 66:231-238

20. Lee CS, Lee DG (2004) Manufacturing of composite sandwich robot structures using the co-cure bonding method. Compos Struct 65:307-318

21. Xue J, Wang W-X, Takao Y, Matsubara T (2011) Reduction of thermal residual stress in carbon fiber aluminum laminates using a thermal expansion clamp. Compos Part A 42:986-992

22. Park SW, Kim HS, Lee DG (2006) Optimum design of the cocured double lap joint composed of aluminum and carbon epoxy composite. Compos Struct 75:289-297

23. Kolesnikov B, Herbeck L, Fink A (2008) CFRP/titanium hybrid material for improving composite bolted joints. Compos Struct $83: 368-380$

24. Leng J, Asundi A (2003) Structural health monitoring of smart composite materials by using EFPI and FBG sensors. Sensors Actuators A 103:330-340

25. Meo F, Merlo A, Rodriguez M, Brunner B, Fleck NA, Lu TJ, Mai SP, Srikantha Phani A, Woodhouse J (2008) Advanced hybrid mechatronic materials for ultra precise and high performance machining systems design. In: Pham DT, Eldukhri EE, Soroka AJ (eds) Innovative production machines and systems, MEC Cardiff University, UK

26. Lin M, Chang F-K (2002) The manufacture of composite structures with a built-in network of piezoceramics. Compos Sci Technol 62:919-939

27. Denkena B, Immel J, Schönherr M (2011) Industrieroboter für spanende Bearbeitungen, wt Werkstattstechnik online 101/9:617-622

28. Brecher C, Flore J, Klatte M, Wenzel C (2012) Machine integrated robust direct measuring devices for the compensation of thermal deformation. In: MM Science Journal, Special Issue, MATAR 2012, Proceedings of the 9th International Conference on Machine Tools, Automation, Technology and Robotics, Sept. 12-14, Prague, Czech Republic

29. Möhring H-C, Wiederkehr P, Lerez C, Schmitz H, Goldau H, Czichy C (2016) Sensor integrated CFRP structures for intelligent fixtures. Procedia Technol 26:120-128

30. Misch S, Welzel F, Möhring H-C (2019) Integrated strain gauge printing in a CFRP structure. J Mach Eng 19(3):74-81

Publisher's Note Springer Nature remains neutral with regard to jurisdictional claims in published maps and institutional affiliations. 